\title{
The Thermal Structure and Temporal Evolution of High-
}

\section{Enthalpy Geothermal Systems}

\author{
Samuel Scott ${ }^{1}$, Thomas Driesner ${ }^{1}$, and Philipp Weis ${ }^{1,2}$ \\ ${ }^{1}$ Department of Earth Sciences, Institute of Geochemistry and Petrology, ETH Zurich, \\ Clausiusstrasse 25, 8092 Zurich, Switzerland. \\ ${ }^{2}$ GFZ German Research Centre for Geosciences, Telegrafenberg, 14473 Potsdam, Germany. \\ Correspondence and requests for materials should be sent to S. S. (email: \\ samuel.scott@erdw.ethz.ch)
}

\section{Abstract}

Numerical modeling is a powerful tool to investigate the response of high-enthalpy geothermal systems to production, yet few studies have examined the long-term evolution and thermal structure of these systems. Here we report a series of numerical simulations of fluid flow and heat transfer around magmatic intrusions which reveal key features of the natural thermal and hydraulic structures of high-enthalpy geothermal systems. We explore the effect of key geologic controls, such as host rock permeability, the emplacement depth and geometry of the intrusion, and temperature-dependent permeability near the intrusion, on the depth and extent of boiling zones, the number and spatial configuration of upflow plumes, and how these aspects evolve over the systems' lifetime. Host rock permeability is a primary control on the general structure, temperature distribution and extent of boiling zones, as systems with high permeability $\left(\geq 10^{-14} \mathrm{~m}^{2}\right)$ show shallow boiling zones restricted to $\leq 1 \mathrm{~km}$ depth, while intermediate permeability $\left(\sim 10^{-15} \mathrm{~m}^{2}\right)$ systems display vertically extensive boiling zones reaching from the surface to the intrusion. Intrusion emplacement depth is a further control, as intermediate permeability systems driven by an intrusion at $\geq 3 \mathrm{~km}$ depth only show boiling above $1 \mathrm{~km}$. If a cooling intrusion becomes permeable at temperatures 
significantly in excess of the critical temperature of water, the enthalpy of the upflow becomes high enough that systems with high permeability show vertically extensive boiling zones, and intermediate permeability systems spatially extensive zones of supercritical water near the intrusion. The development of multiple, spatially separated upflow plumes above a single intrusive body is characteristic of systems with high permeability and deep emplacement depth. Depending on the primary geologic controls, systems exhibit characteristic lateral and vertical gradients in pressure, temperature and enthalpy relative to the intrusive heat source which may aid in geothermal exploration and interpretation of field measurements.

\section{Introduction}

Most of the electricity harnessed from geothermal heat is generated from magmadriven high-enthalpy geothermal systems. The natural lifetime of a high-enthalpy geothermal system generated by a single magmatic intrusion is typically on the order of $\sim 10^{4}$ years (Cathles et al., 1997; Hayba and Ingebritsen, 1997), while large-scale power production from magma-driven geothermal systems has at most proceeded for decades. Therefore, modern geothermal reservoir engineering makes the plausible assumption that a nearly steady, "natural state" of a given system can be established in a model and then used as a reference for evaluating and predicting changes to a reservoir during operation (Bödvarsson et al., 1986; O'Sullivan et al., 2001). Geothermal systems with a long-term production history, such as Lardarello (Romagnoli et al., 2010) and Wairakei (O'Sullivan et al., 2009), permit reservoir modelers to use a history of field measurements such as down-hole pressures, temperatures, flow rates and enthalpies, to calibrate inverse models with parameter estimation and history matching (Finsterle, 2007; Aradóttir et al., 2012). While these reservoir models are constructed with input from geological, geophysical, geochemical and hydrological studies, 
geothermal reservoir engineers are often tasked to build preliminary models with little or no development history (Pritchett, 2007). In these instances, a conceptual model describing the thermal and hydrological features of magma-driven geothermal systems is crucial to inform estimates of a field's potential electricity generation capacity and decision-making concerning the location and depth of exploration wells (Bödvarsson, 1969; Fridleifsson, 1978; Cumming, 2009).

In contrast to the numerous efforts to model the evolution of a reservoir during production, rather few studies have focused on the long-term, undisturbed evolution and structure of high-enthalpy geothermal systems. The first numerical simulations of hydrothermal convection around magmatic intrusions demonstrated that the system behavior and lifetime is strongly impacted by host rock permeability (Norton and Knight, 1977; Cathles, 1977; Norton and Taylor, 1979). Subsequent studies included the full thermodynamics of boiling water to magmatic conditions and demonstrated that host rock permeability controls the development of boiling zones and the overall thermal structure of a system (Hayba and Ingebritsen, 1997; Hurwitz et al., 2003). While the near-surface parts of systems are at boiling conditions through the main and later parts of system evolution, systems may have different plume geometries, deep thermal structures, and hydraulic behavior depending on the host rock permeability and the stage in the system lifetime. Relatively little of this knowledge seems to have reached larger parts of the geothermal community and a number of aspects - such as the natural enthalpy distribution at depth - have not been addressed in published studies.

Here we report and analyze a series of two-dimensional numerical simulations of pure water flow around a magmatic intrusion building on earlier pioneering studies (Norton and Knight, 1977; Cathles, 1977; Hayba and Ingebritsen, 1997). We describe key features of the natural - undisturbed by production - thermal and hydraulic structures of high-enthalpy 
systems and their evolution over the lifetime of a system. We explore the effects of host rock permeability, the emplacement depth and geometry of the intrusion, and temperaturedependent permeability near the intrusion on the the depth and extent of boiling zones, the number of upflow plumes produced per intrusion, and the system's temporal evolution and lifetime. We show how the evolution of the thermal and hydraulic structures of high-enthalpy

geothermal systems respond systematically to variation of these primary parameters over a relatively small range. Lastly, we condense these systematics to a set of key findings that may be useful in exploration and resource assessment.

\section{Conceptual model of magma-driven geothermal systems}

The importance of subsurface magmatic intrusions as heat sources driving the convective circulation of groundwater in many high-enthalpy systems has long been recognized (White, 1957, 1965, 1967; Bödvarsson, 1961; Banwell, 1963; White et al., 1971; Stefánsson and Björnsson, 1982; Henley and Ellis, 1983; Arnórsson, 1995). Figure 1 illustrates the conceptual anatomy of a magma-driven, boiling geothermal system. Convection develops in permeable rock above a magmatic intrusion, which itself may be partially molten or completely crystallized and still at high temperatures. The intrusion is impermeable to groundwater flow and provides heat to the surroundings by heat conduction (plus a minor radiative contribution). On the outer edge of the intrusive caparace, the mode of rock deformation transitions from ductile creep to brittle fracture, allowing the development of permeable fluid flow pathways (Cathles, 1993; Fournier, 1999). Buoyancy forces resulting from the difference between the higher 'cold' hydrostatic vertical pressure gradient, controlled by the density of cold groundwater far from the intrusion, and the lower 'hot' hydrostatic gradient within the hydrothermal system cause surface-derived meteoric waters to circulate downards towards the intrusion where it is heated and ascends in upflow plumes. If they are sufficiently hot, these rising hydrothermal fluids depressurize until a depth is reached 
where the fluid pressure equals the vapor saturation pressure, resulting in the separation of liquid and vapor phases (i.e., boiling). Within the boiling zones, systems show temperatures
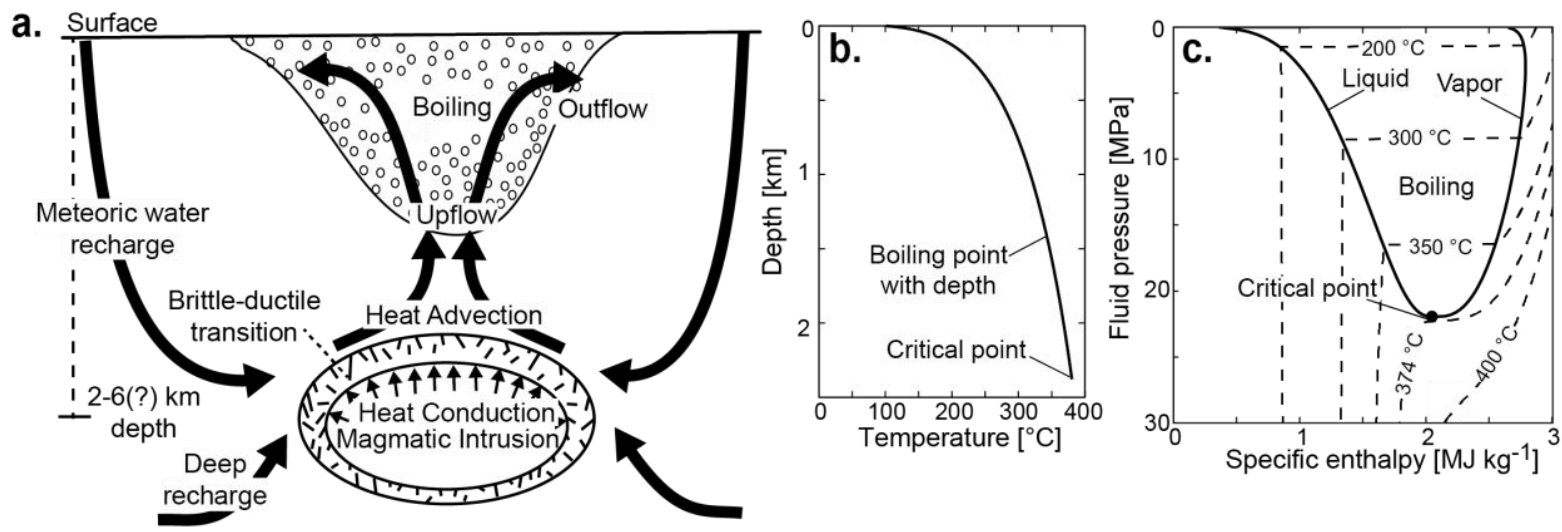

Figure 1. Main features of high-enthalpy geothermal systems. a. Conceptual model of a high-enthalpy system showing schematic fluid flow paths, the brittle-ductile transition around a magmatic intrusion, and a boiling zone near the surface. Modified after White (1967), White et al. (1971), and Arnórsson et al. (2007). b. Temperaturedepth projection of the boiling point with depth curve (see text), calculated for a fluid column consisting of vapor-saturated liquid, terminating at the critical point of pure water $\left(374{ }^{\circ} \mathrm{C}, 22.05 \mathrm{MPa}\right)$. c. Pressure-enthalpy projection of a phase diagram for pure water, showing the specific enthalpy of liquid and vapor at two-phase (boiling) conditions and isotherms (dashed lines).

approximating the 'boiling point with depth' curve (Fig. 1b). The volumetric saturation of high-enthalpy, low-density vapor and lower enthalpy, high-density liquid phase vary based on the bulk fluid enthalpy and the thermodynamic properties of $\mathrm{H}_{2} \mathrm{O}$ (Fig. 1c). Fluid pressure and depth are not interchangeable variables in boiling systems, since the maximum depth and enthalpy of boiling zones may vary and the pressure field is also controlled by fluid dynamics and thermodynamic properties. However, systems dominated by liquid water with pressure gradients close to near liquid-hydrostatic are far more common than vapor-dominated systems (White, 1965), which show near-vaporstatic pressure gradients within boiling zones (Grant and Bixley, 2005).

Numerical models of fluid flow and heat transfer provide a quantitative basis for conceptual understanding of the thermo-hydrological structure and transient behavior of geothermal systems. Industry-standard modeling tools impose a temperature limit of $350{ }^{\circ} \mathrm{C}$ (Pruess et al., 1999), obliging reservoir modelers to mimic the deep parts of the convective 
system by adapting thermal and/or flux boundary conditions (e.g., Gunnarsson et al., 2010). However, in recent years, some tools have been developed to handle these extreme conditions given the interest in targeting deeper and hotter resources worldwide (Croucher and O’Sullivan, 2008; Magnusdóttir and Finsterle, 2015). In the standard approach to reservoir modeling (e.g., O'Sullivan et al., 2001), the 'natural state' of the system (i.e., preexploitation) is taken to be the steady-state configuration resulting under imposed model initial and boundary conditions. However, real geothermal systems may not approach a true steady-state. Major characteristics of a geothermal system, such as the subsurface temperature distribution, the depth of boiling zones, and the location of surface expressions change over time as the intrusive heat source is progressively cooled. Thus, time-dependent behavior has implications for the electrical power generation potential of such systems as well as the sustainability of various exploitation strategies (Axelsson, 2010).

Previous studies including a transiently cooling heat source have described the important control of rock permeability on the thermal structure and temporal evolution of geothermal systems (Norton and Knight, 1977; Cathles, 1977; Hayba and Ingebritsen, 1997; Cathles et al., 1997; Driesner and Geiger, 2007). Regional-scale permeability in geothermal systems is in the range of $10^{-14}-10^{-16} \mathrm{~m}^{2}$ (Björnsson and Bödvarsson, 1990; Manning and Ingebritsen, 1999). Host rock permeability is reduced near the brittle-ductile transition, and below a permeability of $\sim 10^{-16} \mathrm{~m}^{2}$ the mode of heat transfer changes from advection to conduction-dominated (Ingebritsen et al., 2006). Higher advective heat and mass fluxes resulting from higher host rock permeability lead to more rapid cooling of the intrusion as well as lower average fluid temperatures and shallower boiling zones (Norton and Knight, 1977; Hayba and Ingebritsen, 1997; Driesner and Geiger, 2007). We recently explained this behavior in terms of fluid mixing, since higher host rock permeability increases the extent to which high-enthalpy fluid rising from the brittle-ductile transition mixes with lower temperature liquid circulating further from the intrusion (Scott et al., 2015). 


\section{Methodology and Model Set-Up}

The governing equations of multi-phase mass and energy conservation are solved using a continuum porous media approach with a pressure-enthalpy-based formulation in a Control Volume-Finite Element Method numerical scheme using the Complex Systems Modeling Platform (CSMP++), which has been described in detail by Weis et al. (2014), and is thus only described briefly in Appendix A. Here, we focus on a description of the model set-up and conceptual justification of the underlying assumptions.

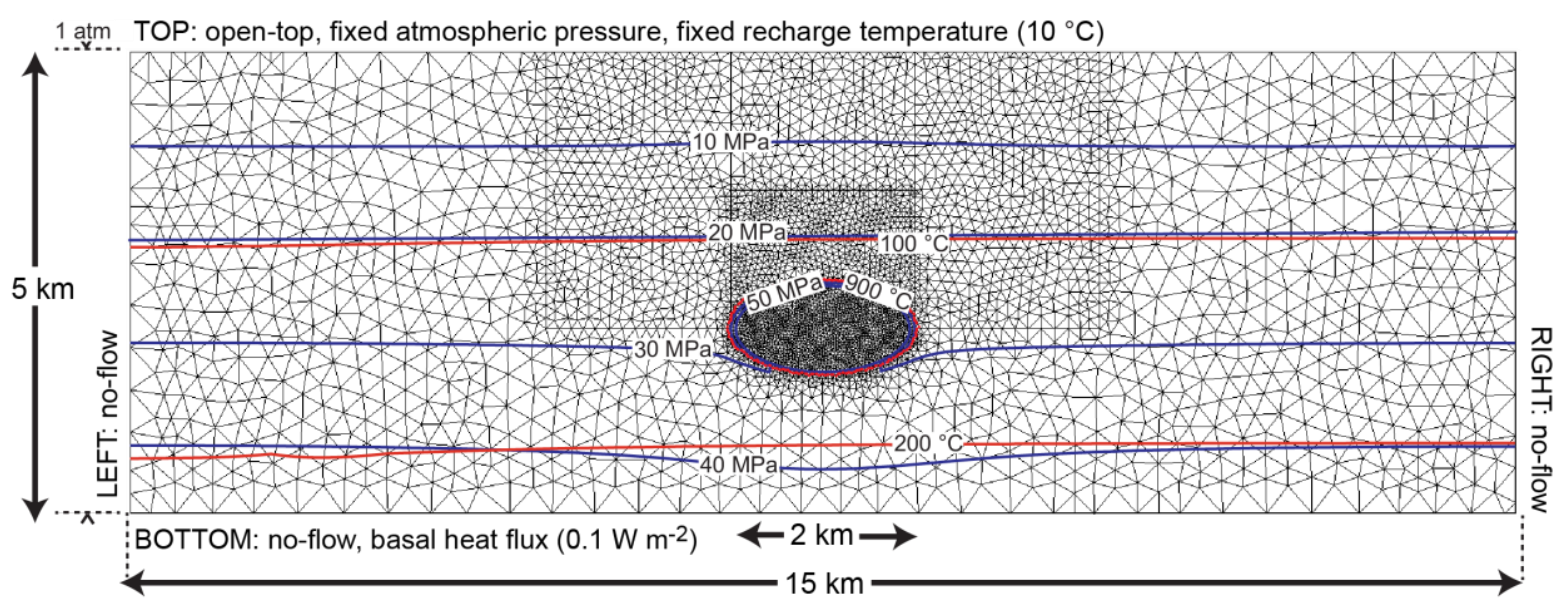

Figure 2. Model set-up and finite element discretization. Initial temperature and pressure distribution is shown with red and blue contours, respectively.

A typical model configuration is given in Fig. 2, for an intrusion centered at $3 \mathrm{~km}$ depth with horizontal and vertical axis lengths of $2 \mathrm{~km}$ and $1 \mathrm{~km}$, respectively. In this study, the term 'emplacement depth' refers to the depth to the top of the intrusion, and is thus $2.5 \mathrm{~km}$ for the example in Fig. 2. The computational domain is $5 \mathrm{~km}$ and $15 \mathrm{~km}$ in vertical and horizontal extent, respectively, and consists of roughly 14,000 elements. Initially, the porous medium is saturated with water and thermally equilibrates with a basal heat flux of $0.1 \mathrm{~W} \mathrm{~m}^{-2}$. The initial pressure distribution is hydrostatic, assuming that the water table coincides with the ground surface and that the topography is flat. The top boundary is fixed at atmospheric pressure, and features a mixed energy boundary condition. In elements where volume flux is upward, fluids are allowed to vent at temperatures of the ascending hydrothermal fluids; 
elements where the volume flux is downward take in fluid at a temperature of $10{ }^{\circ} \mathrm{C}$. This simulates the effect of recharge of cold meteoric water, sufficient to maintain a stable elevation of the water table. The other boundaries are no-flow boundaries, placed sufficiently far from the heat source that they do not affect fluid convection near the intrusion.

The initial properties of the host rock and intrusion are listed in Table 1.

Table 1. Initial rock and intrusion properties.

\begin{tabular}{c|c|c|}
\hline Initial rock property & Host rock & Magmatic intrusion \\
\hline Temperature $\left[{ }^{\circ} \mathrm{C}\right]$ & Geothermal gradient ${ }^{\mathrm{a}}$ & 900 \\
Porosity [-] & 0.1 & 0.05 \\
Permeability [ $\left.{ }^{2}\right]$ & $10^{-14}-10^{-16}$ & Temperature-dependent (see text) \\
Heat capacity (isobaric) $\left[\mathrm{J} \mathrm{kg}^{-1}{ }^{\circ} \mathrm{C}^{-1}\right]$ & 880 & Temperature-dependent (see text) \\
Density $\left[\mathrm{kg} \mathrm{m}^{-3}\right]$ & 2,750 & 2,750 \\
Thermal conductivity $\left[\mathrm{W} \mathrm{m}{ }^{-1}{ }^{\circ} \mathrm{C}^{-1}\right]$ & 2.25 & 2.25 \\
\hline a. Corresponding to a basal heat flux of $0.1 \mathrm{~W} \mathrm{~m}^{-2}$ or roughly $45^{\circ} \mathrm{C} \mathrm{km}^{-1}$ depth
\end{tabular}

The fluid is assumed to be pure water with the equation of state of Haar et al. (1984). At the onset of simulation time, fluid within the pore space of the intrusion is set to a temperature of $900{ }^{\circ} \mathrm{C}$ and lithostatic pressure, describing an instantaneous intrusion of magma into the upper crust. As described below, host rock permeability is homogenous and isotropic, and temperature-dependent near the intrusion. The effect of latent heat of crystallization is taken into consideration with a temperature-dependent rock heat capacity, which doubles from 880 $\mathrm{J} \mathrm{kg}^{-1}{ }^{\circ} \mathrm{C}^{-1}$ at temperatures below $650{ }^{\circ} \mathrm{C}$ to $1760 \mathrm{~J} \mathrm{~kg}^{-1}{ }^{\circ} \mathrm{C}^{-1}$ at temperatures greater than 700 ${ }^{\circ} \mathrm{C}$. The host rock permeability, the brittle-ductile transition temperature, and the initial geometry and depth of the intrusion are varied in a systematic way in order to identify the effect of these factors on the thermal structure and transient behavior of the geothermal system.

The model geometry is symmetric, but the irregular mesh is asymmetric (Fig. 2). For computational reasons, earlier modeling studies used half-space models and placed a no-flow boundary condition at the center of the upflow zone, representing a forced assumption of a symmetric hydrothermal system. As hydrothermal plumes are not always centered, we also 
wanted to investigate which conditions favor two quasi-symmetric plumes or asymmetric plume development with preferential upflow to one side of the 2D domain.

In numerical simulations, very small differences, such as irregular mesh orientation or even numerical precision, can trigger non-linear feedbacks that influence the dynamics of fluid flow. At early times, differences in mesh orientation around a symmetrical intrusion may result in small differences in temperature on the sides of an intrusion. Since fluid viscosity decreases with higher temperature, fluid flow velocities will be slightly higher where there are higher temperatures. With continued propagation over time, an initially small temperature difference may lead to large-scale asymmetries in plume development. In natural systems, geological heterogeneities may have the same triggering effect. However, the mesh resolution of our models is high enough that fluid flow is not mesh-dependent or -dominated. Using irregular meshes of triangular meshes further allowed us to approximate magma chambers with elliptical shapes in a geologically more realistic way then orthogonal meshes of finite difference grids.

\subsection{Permeability structure}

In our simulations, we represent the host rock as a continuum porous medium with a uniform, isotropic permeability ranging from $10^{-14} \mathrm{~m}^{2}$ to $10^{-16} \mathrm{~m}^{2}$ to assess its first-order effect. A permeability of $10^{-14} \mathrm{~m}^{2}$ is hereafter referred to as high permeability, $10^{-15} \mathrm{~m}^{2}$ intermediate, and $10^{-16} \mathrm{~m}^{2}$ low, because heat transfer is conduction-dominated below this value (Ingebritsen et al., 2006). The influence of heterogeneous and possibly anisotropic permeability distribution is beyond the scope of our study. A key feature of our simulations is the temperature-dependent permeability of the magma chamber and the host rock, which is essential for representing the transition from conduction- to advection-dominated heat transfer around the intrusion. We adapt a formulation first introduced by Hayba and Ingebritsen 
(1997), in which permeability decreases log-linearly above a selected temperature from the background, host-rock permeability $\left(k_{o}\right)$ to a value of $10^{-22} \mathrm{~m}^{2}$ (Appendix B). The temperature at which permeability starts to decrease $\left(T_{\mathrm{BDT}}\right)$ is interpreted as the onset of the brittle-ductile transition (BDT). While a $T_{\mathrm{BDT}}$ of $360{ }^{\circ} \mathrm{C}$ used by Hayba and Ingebritsen (1997) is appropriate for quartz-bearing rocks at normal crustal strain rates (Fournier, 1991, 1999), we also investigate the effect of increasing this temperature to 450 and $550{ }^{\circ} \mathrm{C}$, based on experimental evidence of brittle deformation at such temperatures in basaltic rocks (Violay et al., 2012, 2015).

\subsection{Intrusion depth and geometry}

The depth and configuration of intrusive bodies are primary factors controlling the location and characteristics of geothermal systems (Sibbett, 1988). While shallow minor intrusions, dykes and small sills are relatively frequent at $1-2 \mathrm{~km}$ depth beneath volcanic systems (e.g., Franzson, 1998), deeper major intrusions are considered to act as the main heat source for geothermal activity in many systems (White, 1957; Bödvarsson, 1961; White et al., 1971; Arnórsson, 1995). Seismic tomography has been used to estimate the depths of magmatic intrusions beneath volcanoes with active geothermal systems (Lees, 2007), although this method currently does not allow precise determination of magma depth. We test the effect of varying the depth to the top of the intrusion from 2 to $3 \mathrm{~km}$.

Similarly, little is known about the geometry of magma bodies beneath geothermal systems. While magma chambers may have shapes ranging from sill-like to dike- or laccolithlike, highly irregular shapes are thermo-mechanically unstable (Marsh, 1989). Thermal and stress considerations suggest that an oblate ellipsoidal shape is the most common magma chamber geometry (Gudmundsson, 2012). Furthermore, some field studies of exhumed magma chambers and associated dike swarms are consistent with an approximately elliptical geometry (Burchardt and Gudmundsson, 2009). While most of our simulations feature an 
oblate ellipsoidal intrusion, we also test the effect of making the intrusion more oblate or prolate. Temperatures within the intrusion decrease monotonically with progressive cooling; replenishment of the magma chamber or repeated intrusive events are not simulated in this study. Although recent studies have begun to model hydrothermal circulation with timevariant intrusive activity (Gunnarsson and Aradóttir, 2014), full consideration of the role of successive intrusive events is beyond the scope of this study.

\section{Results}

\subsection{Temporal evolution of geothermal systems}

The temporal evolution of a geothermal system can be divided into an incipient, main and waning stage (Fig. 3). The three stages have distinct thermal structures that we illustrate by thermal profiles taken at the center of the model (Fig. 3d) and distinct lateral pressure variations that we show as horizontal pressure profiles at $1 \mathrm{~km}$ depth (Fig. 3e).

\subsubsection{Incipient stage}

During the incipient stage (Fig. 3a), one or more plumes of heated water ascend above the intrusive heat source. Cold, dense groundwater opposes the upward movement of the hot, low-density fluid from the intrusion. Near-surface temperatures remain at the initial, normal geothermal gradient, and are underlain by a plume head with a rapid temperature increase over a span of 200-300 m, below which temperatures are near isothermal or follow the boiling point with depth profile (Fig. 3d, blue line). Fluid pressure increases towards the center of the upflow to values of ca. $1 \mathrm{MPa}$ above cold hydrostatic (Fig. 3e, blue line), an indication that the hot upflow plumes exert a force against cold groundwater in order to ascend to the surface. Because of the higher pressures, temperatures and enthalpies inside the plume at this stage are higher than those that develop at the same depths in the subsequent main stage. In 

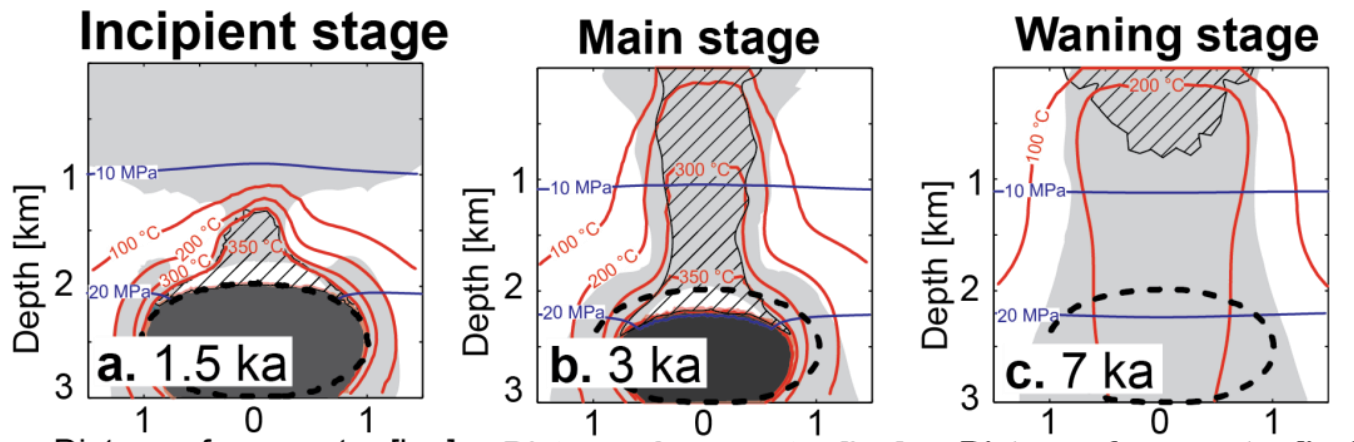

Distance from center [km]

\section{Distance from center [km] Distance from center [km]}
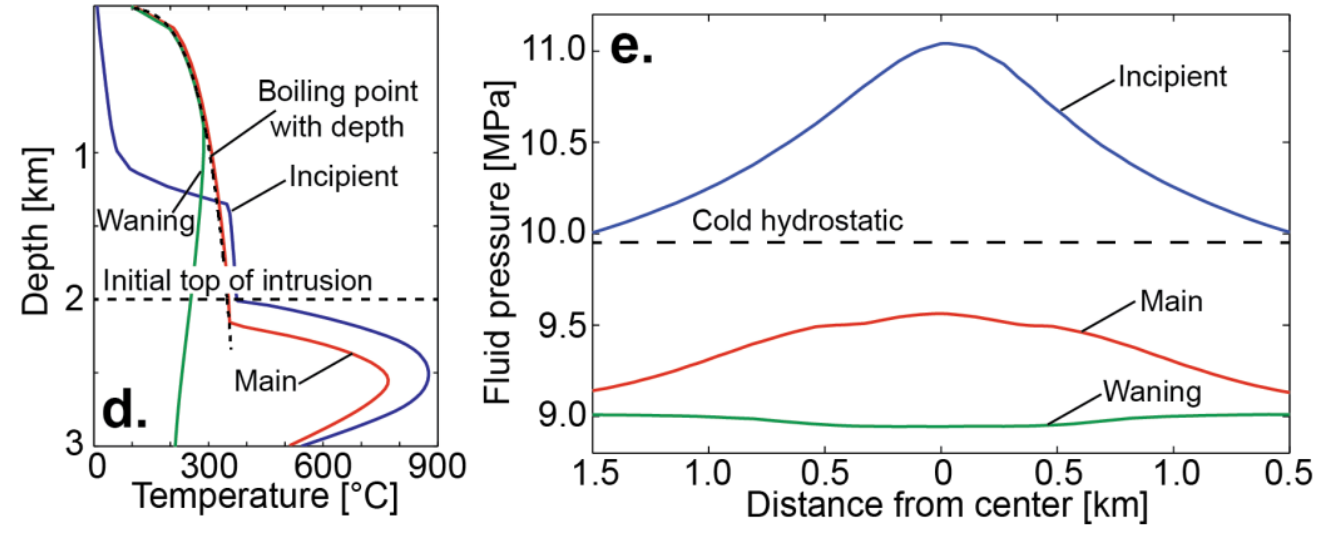

Figure 3. The temporal evolution of high-enthalpy geothermal systems can be divded into an a. incipient, b. main, and c. waning stage, as illustrated by an example simulation (see text). The upflow plume, defined as the area where the vertical component of liquid pore velocities is positive upwards, is shown in grey. Zones where liquid flows downward towards the intrusion are shown in white. The different stages in the evolution of these systems are associated with characteristic vertical temperature profiles (as shown in d.) and horizontal pressure profiles at $1 \mathrm{~km}$ depth (e.).

our simulations, excess pressures of $\sim 0.5 \mathrm{MPa}$ above cold hydrostatic occur at depths as shallow as $100 \mathrm{~m}$ when the plume head has reached about $1 \mathrm{~km}$ depth.

\subsubsection{Main stage}

The main stage commences when the boiling upflow plume reaches the surface and the upflowing fluid no longer has to work against overlying colder groundwater. During the main stage, systems typically display vertically extensive boiling zones, which in extreme cases may reach from the surface to the top of the intrusion (Fig. 3d, red line). Vertically extensive boiling zones may contain areas where liquid flows downward and vapor upwards in a heat pipe-like structure (Woods, 1999; Coumou et al., 2008). Controls on the occurrence and extent of boiling zones will be presented in sections 4.2-4.5. Plume breakthrough brings lower-density fluid to the surface, so fluid pressures reflect 'hot hydrostatic' conditions and are $0.7-1.5 \mathrm{MPa}$ below cold hydrostatic at $1 \mathrm{~km}$ depth (Fig. 3e, red line). Within the boiling 
zones, the 'hot hydrostatic' pressure gradient is a function of the fluid density, which depends on the fluid's bulk enthalpy and vapor saturation. Even though the vapor content of boiling zones is highest in the middle of the upflow plume (as shown in later sections), fluid pressures at $1 \mathrm{~km}$ depth increase towards the middle of the boiling zone. Thus, the driving force for vertical upflow, the difference between the actual vertical pressure gradient and the hot liquidhydrostatic pressure gradient, is maximized in the center of the upflow.

\subsubsection{Waning stage}

In the waning stage, when temperatures in the intrusive heat source have decreased below the brittle-ductile transition temperature, the intrusion becomes permeable and the remaining heat is removed relatively quickly by the convecting water. While the thermal and hydraulic structure of the system's upper parts remain quite similar to those of the main stage, including laterally extensive boiling, cold meteoric water flows toward the cooled intrusion and cools the deeper parts of the system. Thus, systems in the waning stage tend to have thermal profiles featuring boiling at the surface and temperature inversions (where temperature decreases with increasing depth) at depths below 0.5-1 km (Fig. 3d, green line). During the waning stage, fluid pressure at $1 \mathrm{~km}$ depth is $0.1-0.5 \mathrm{MPa}$ lower than during the main stage, and in contrast to the main stages, fluid pressure decreases slightly towards the center of the upflow (Fig. 3e, green line).

\subsection{Effect of host rock permeability on geothermal system structure}

Host rock permeability is a primary control on the general structure, temperature distribution, and extent of boiling zones in geothermal systems. Systems with high host-rock permeability generally display near-isothermal upflow of single-phase liquid in their deeper parts and boiling in their shallow parts. Intermediate-permeability systems may develop boiling zones extending from the surface to the top of the intrusion and, accordingly, show a temperaturedepth distribution that tends to follow the boiling curve with depth. 

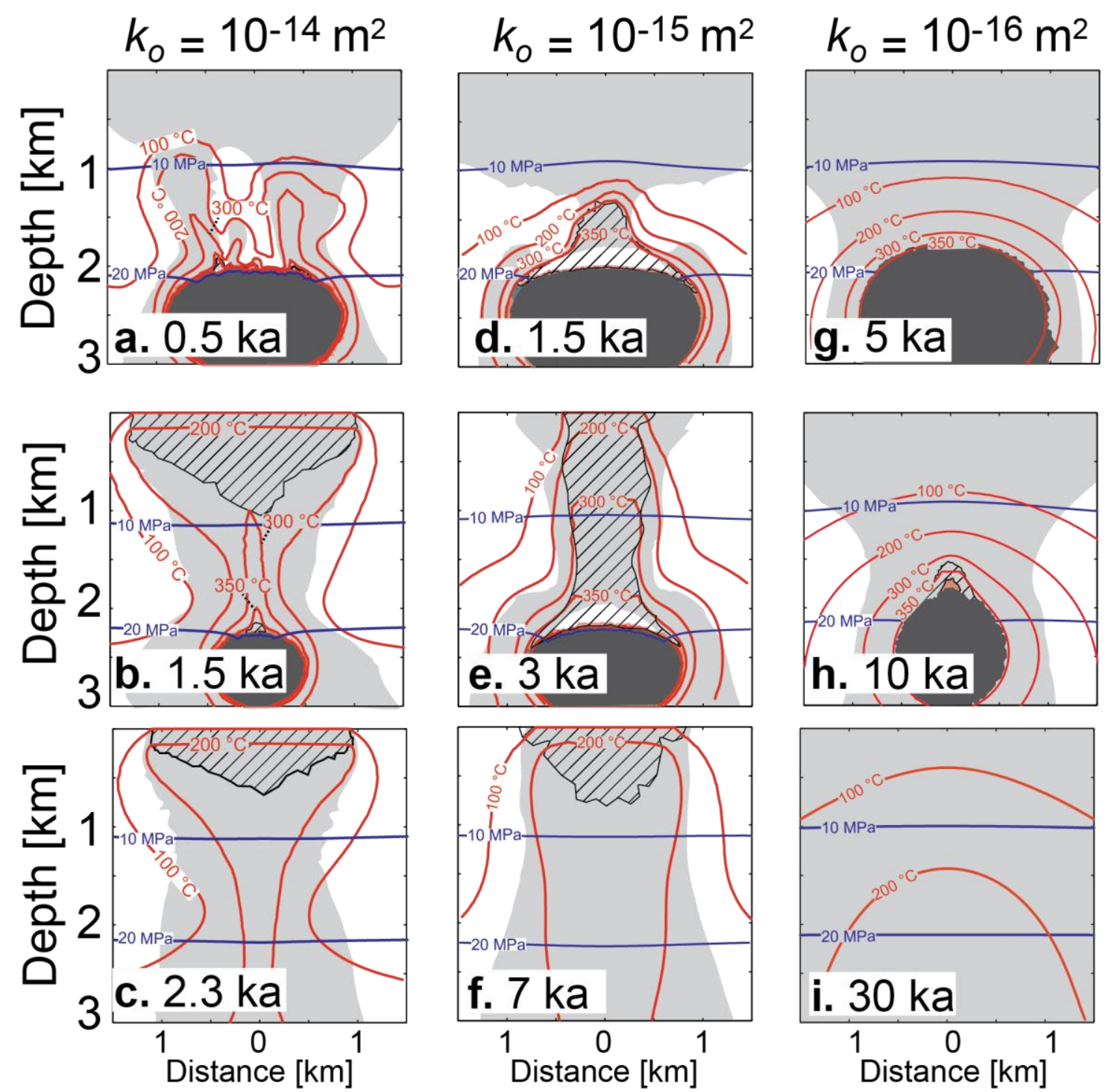

Figure 4. Effect of host rock permeability on the transient development of geothermal systems for an intrusion with an emplacement depth of $2 \mathrm{~km}$. Host rock permeability is set to $10^{-14} \mathrm{~m}^{2}$ (a.-c.), $10^{-15} \mathrm{~m}^{2}$ (d.-f.), or $10^{-16}$ $\mathrm{m}^{2}$ (g.-i.). The simulation time of the snapshot is shown in lower left. Isotherms and isobars are shown in red and blue, respectively. The light grey areas show the location of the upflow plume, defined as areas where the vertical component of the liquid pore velocity is positive. The dark grey areas show the intrusion, which is characterized by permeability $>10^{-16} \mathrm{~m}^{2}$. Areas with boiling are highlighted with diagonal lines.

The thermal structure of a system with high host-rock permeability undergoes significant changes from incipient to waning stages. For high host-rock permeability and an emplacement depth of $2 \mathrm{~km}$, two $\sim 300{ }^{\circ} \mathrm{C}$ liquid plumes develop rapidly after emplacement of the intrusion (Fig. 4a). Upflow reaches the surface within $0.8 \mathrm{ky}$ and merges into a single plume at depth by $1.5 \mathrm{ky}$ (Fig. 4b). Throughout the main stage, there is a single upflow zone centered on the intrusion with a boiling zone at $<1 \mathrm{~km}$ depth shaped like an inverted teardrop. 
A narrow $(\sim 100 \mathrm{~m})$ upflow zone is nearly isothermal $\left(\sim 300^{\circ} \mathrm{C}\right)$ and underlies the center of the boiling zone. During the waning stage, boiling persists in the upper $0.5 \mathrm{~km}$ for $3-4 \mathrm{ka}$ after the heat source has cooled completely (Fig. 4c).

Fig. 4d-f depicts system evolution for an intermediate host rock permeability of $10^{-15}$ $\mathrm{m}^{2}$ and emplacement depth of $2 \mathrm{~km}$ (i.e., the same simulation as shown in Figure $3 \mathrm{a}-\mathrm{c}$ ). During the incipient stage, a single boiling plume with temperatures $>300{ }^{\circ} \mathrm{C}$ develops over the center of the intrusion, reaching the surface within $3 \mathrm{ka}$ (Fig. 4e). The upflow plume is at boiling conditions from the surface to ca. $2.5 \mathrm{~km}$ depth throughout the main stage. The width of the boiling upflow is nearly constant but increases in the near vicinity of the intrusion (Fig. 4e) After the intrusion cools enough to become permeable, the depth of boiling decreases rapidly to $\sim 1 \mathrm{~km}$. However, as the system cools from the bottom up throughout the waning stage, the upper parts of the system appear similar to the main stage, with boiling persisting at the surface for $5 \mathrm{ka}$ after the end of the main stage (Fig. 4f).

For a low host rock permeability of $10^{-16} \mathrm{~m}^{2}$, heat transfer is dominated by thermal conduction and fluid convection is insignificant. This is apparent during the incipient stage, as the isotherms around the intrusion are roughly concentric, without any indication of plume formation (Fig. 4g). The very slowly ascending fluid causes no thermal perturbation, but rather loses heat as it rises from the intrusion. Boiling is restricted to small zones close to the intrusion (Fig. 4h). The lack of plume development prevents the system from reaching a main-stage configuration before the intrusion cools (Fig. 4i).

\subsection{Effect of intrusion depth on geothermal system structure}

Intrusion depth is a major control on whether one or more spatially separated geothermal reservoirs may form in the upper parts of a geothermal system driven by a single intrusive body. We investigate the variations imposed by changing the emplacement depth (as defined in Section 3) from 2 to $3 \mathrm{~km}$. 

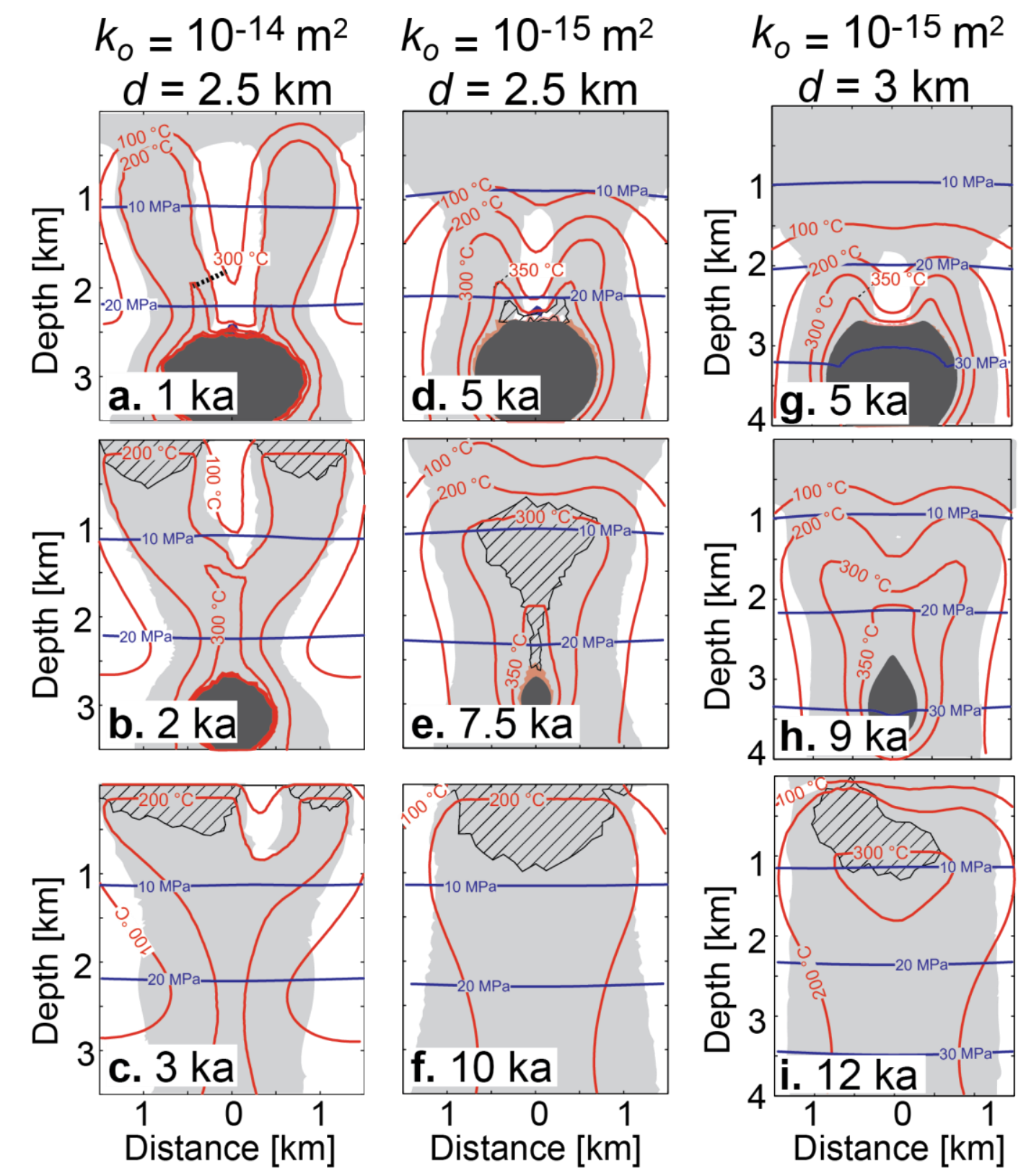

Figure 5. Effect of intrusion emplacement depth on the transient development of geothermal systems. In a.-f., the emplacement depth is $2.5 \mathrm{~km}$ and host rock permeability is set to $10^{-14} \mathrm{~m}^{2}$ (a.-c.) or $10^{-15} \mathrm{~m}^{2}$ (d.f.). In g.-i., the emplacement depth is $3 \mathrm{~km}$ and host rock permeability is set to $10^{-15} \mathrm{~m}^{2}$. Coloring is the same as in Figure 4.

While systems with a heat source located at $2 \mathrm{~km}$ depth (as described in the previous section) normally develop single upflow plumes, systems with a heat source located at $2.5 \mathrm{~km}$ depth may develop multiple plumes that tend to merge at depth as the system evolves. Due to the longer ascent path and higher pressures near the intrusion, these systems are less likely to reach the main stage configuration, and instead exhibit shallower boiling zones occurring at later times in the system evolution. 
A system with an emplacement depth of $2.5 \mathrm{~km}$ and a high host rock permeability develops two distinct plumes over the margins of the intrusion during the incipient stage (Fig. 5a). The plumes merge at depth during the main stage of the system evolution, while in the upper $1.5 \mathrm{~km}$ they continue to diverge into the pathways previously heated by the ascending plumes. A zone of downward-circulating cold $\left(<100{ }^{\circ} \mathrm{C}\right)$ water separates the two shallow boiling zones (Fig. 5b). During waning stages, the system boils near the surface for more than $3 \mathrm{ka}$ after the heat source has cooled completely (Fig. 5c).

Multiple plumes also develop in a system with intermediate host rock permeability and at the same emplacement depth (Fig. 5d-f). During the incipient stage, two upflow plumes develop, with small boiling zones at the base of the plumes at temperatures $>350{ }^{\circ} \mathrm{C}$ (Fig. $5 \mathrm{~d}$ ). As the system evolves, the plumes merge at the base, forming a more extensive deep boiling zone centered on the intrusion (Fig. 5e). Because the thermal front must travel a greater distance upwards, compared to the shallower intrusion, the intrusion cools below the brittleductile transition temperature before boiling occurs at the surface $(\sim 8 \mathrm{ka})$; no clear main stage configuration develops. The system has a long waning phase as the maximum depth of boiling decreases from $2 \mathrm{~km}$ to the surface over $\sim 6 \mathrm{ka}$ (Fig. 5f).

Deep boiling zones near the intrusion cannot form in a system with an emplacement depth of $3 \mathrm{~km}$ and intermediate host-rock permeability because the fluid pressure above the intrusion exceeds the critical pressure of water (22.01 MPa). Two liquid plumes develop over the margins of the intrusion during the incipient stage (Fig. $5 \mathrm{~g}$ ), and merge at depth before the plumes reach the surface (Fig. 5h). Boiling is restricted to shallow depths $(<1.5 \mathrm{~km})$ and later stages of system development (Fig. 5i). A nearly identical thermal structure develops even if the emplacement depth of the intrusion is $6 \mathrm{~km}$ (Appendix C), suggesting that the depth range of 2-3 km is adequate to demonstrate the sensitivity of thermal structure to intrusion depth. 


\subsection{Effect of intrusion geometry on number and thermal structure of upflow zones}

The width and shape of the intrusion influences the number and spacing of upflow zones at depth as well as the location and width of associated surface expressions. More oblate (sill-like) intrusions tend to develop multiple upflow zones, while more prolate (dikeor stock-like) intrusions tend to form a single upflow. Although larger intrusions produce wider upflow zones, the thermal structure of the upflow is nearly identical for different intrusion geometries and depends more on host rock permeability and intrusion depth. Figure 6 compares the evolution of the geothermal systems above a 4-km-wide oblate intrusion at 2 km (Fig. 6a-c) and 3 km (Fig. 6d-f) emplacement depth, both at intermediate host rock permeability.

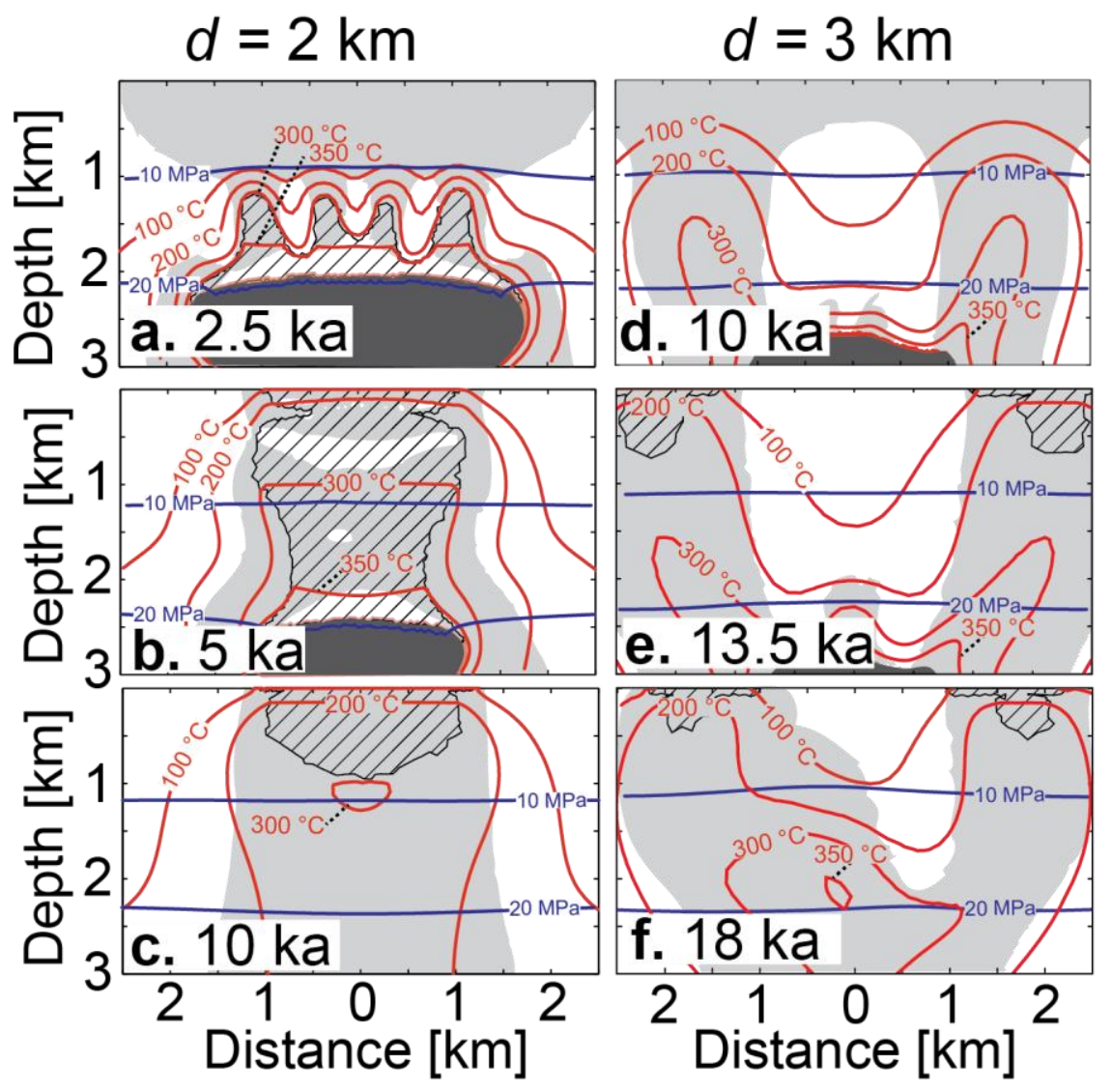

Figure 6. Effect of intrusion emplacement depth on the transient development of geothermal systems driven by a large, oblate intrusion. The emplacement depth is $2 \mathrm{~km}$ (a.-c.) or $3 \mathrm{~km}$ (d.-f.), and host rock permeability is set to $10^{-15} \mathrm{~m}^{2}$. Coloring is the same as in Figure 4.

For the wide intrusion emplaced at shallow $(2 \mathrm{~km})$ depth (Fig. 6a-c), the overall evolution is similar to the smaller elliptical intrusion emplaced at the same depth (Fig. 4d-f). 
Four boiling plumes at temperatures $>300{ }^{\circ} \mathrm{C}$ develop above the intrusion at early stages (Fig. 6a). By $5 \mathrm{ka}$, these merge to form a single, wide, boiling upflow centered over the intrusion (Fig. 6b). Although the intrusion is initially twice as wide as in Fig. 4d-f, it cools below the brittle-ductile transition temperature only $\sim 3$ ky later than the narrower intrusion.

A system with a deeper $(3 \mathrm{~km})$ large oblate intrusion displays multiple upflow plumes, does not develop deep boiling zones, and never develops a main stage configuration (Fig. 6df), similar to a comparable system with the smaller intrusion (Fig. 5g-i). Two plumes rise over the margins of the intrusion but due to the wide intrusion, never fully merge in the center. The incipient stage lasts longer than in the shallow case because only two plumes form, and these plumes need to travel a greater distance. While the shallow oblate intrusion had a vertically extensive boiling zone throughout the main stage (Fig. 6c), the deep system only develops boiling at depths $>1 \mathrm{~km}$. Throughout the waning stage, two minor and very shallow boiling zones at the surface overlie these plumes, and are separated by a zone of lower temperature, sub-boiling liquid (Fig. 6f).

Fig. 7 shows systems with a prolate intrusion that has the same initial size as that in Fig. 4-5 but has been rotated by $90^{\circ}$, and compares systems with emplacement depth $1.5 \mathrm{~km}$ (Fig. 7 a-c) to $2.5 \mathrm{~km}$ (Fig. 7d-f). Systems emplaced at a depth of $1.5 \mathrm{~km}$ (Fig. 7a-c), geothermal systems develop upflow zones that boil over the entire depth to the brittle-ductile transition. However, even though the prolate geometry causes systems to develop a single, focused upflow zone and increases the enthalpy of the fluid upflow, this effect is insufficient to cause boiling below $1.5 \mathrm{~km}$ depth if the intrusion is emplaced at depths $\geq 2.5 \mathrm{~km}$ (Fig. $7 \mathrm{~d}-\mathrm{f}$ ). 

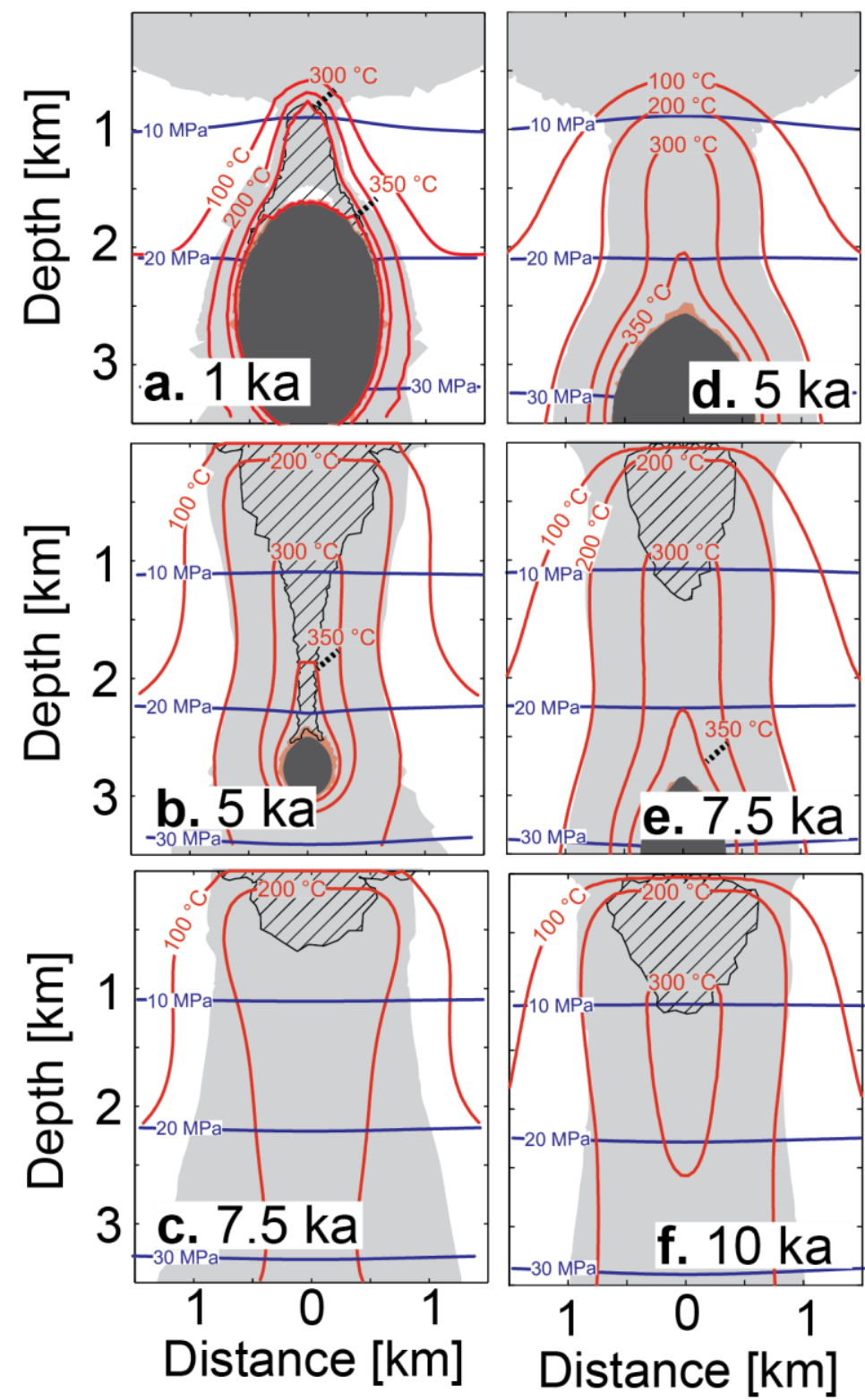

Figure 7. Effect of intrusion emplacement depth on the transient development of geothermal systems driven by a prolate intrusion. The emplacement depth is $1.5 \mathrm{~km}(\mathbf{a}$.c.) or $2.5 \mathrm{~km}$ (d.-f.), and host rock permeability is set to $10^{-15} \mathrm{~m}^{2}$. Coloring is the same as in Figure 4. 


\subsection{Effect of temperature dependence of permeability near the intrusion}

If host rocks surrounding an intrusion remain permeable to higher temperatures, higher enthalpies and temperatures develop in the geothermal system. As discussed in section 3.2, the onset temperature of the brittle-ductile transition, $T_{B D T}$, may vary with rock type and strain rate. The simulations in Figs. $4-7$ used a $T_{\mathrm{BDT}}$ of $360{ }^{\circ} \mathrm{C}$, considered an appropriate value for quartz-bearing rocks (Fournier, 1991, 1999). The effect of increasing $T_{\mathrm{BDT}}$ to $450{ }^{\circ} \mathrm{C}$ or 550 ${ }^{\circ} \mathrm{C}$, as is likely for basaltic rocks (Violay et al., 2012, 2015) or silicic rocks at high tectonic strain rates, strongly depends on host rock permeability. For high permeability systems, this change increases the enthalpy of the upflow zone and the maximum depth of boiling zones, which may then extend to the top of the intrusion. In contrast, intermediate permeability systems with $T_{\mathrm{BDT}} \geq 450{ }^{\circ} \mathrm{C}$ form extensive zones of supercritical geothermal resources, defined as areas where temperature and enthalpy exceed the critical values $\left(373.986{ }^{\circ} \mathrm{C}, 2.086\right.$ MJ $\mathrm{kg}^{-1}$ ) and rock permeability exceeds $10^{-16} \mathrm{~m}^{2}$ (Scott et al., 2015).

Figure 8 compares snapshots from six different simulations with $T_{\mathrm{BDT}}$ of $360{ }^{\circ} \mathrm{C}$ (Fig. $8 \mathrm{a}, \mathrm{d}$ ), $450^{\circ} \mathrm{C}$ (Fig. 8b,e) or $550^{\circ} \mathrm{C}$ (Fig. 8c,f), a host rock permeability of $10^{-14}$ (Fig. 8a-c) or $10^{-15} \mathrm{~m}^{2}$ (Fig. 8d-f) and a constant initial intrusion emplacement depth of $2.5 \mathrm{~km}$. Fluid enthalpy contours superimposed onto the snapshots (black dashed lines) illustrate how increasing $T_{\mathrm{BDT}}$ leads to higher enthalpy systems with more extensive and deeper boiling zones. It should be noted that these enthalpies represent the natural, undisturbed enthalpy of fluid reservoirs, not the production enthalpy of wells drilled into such reservoirs. 


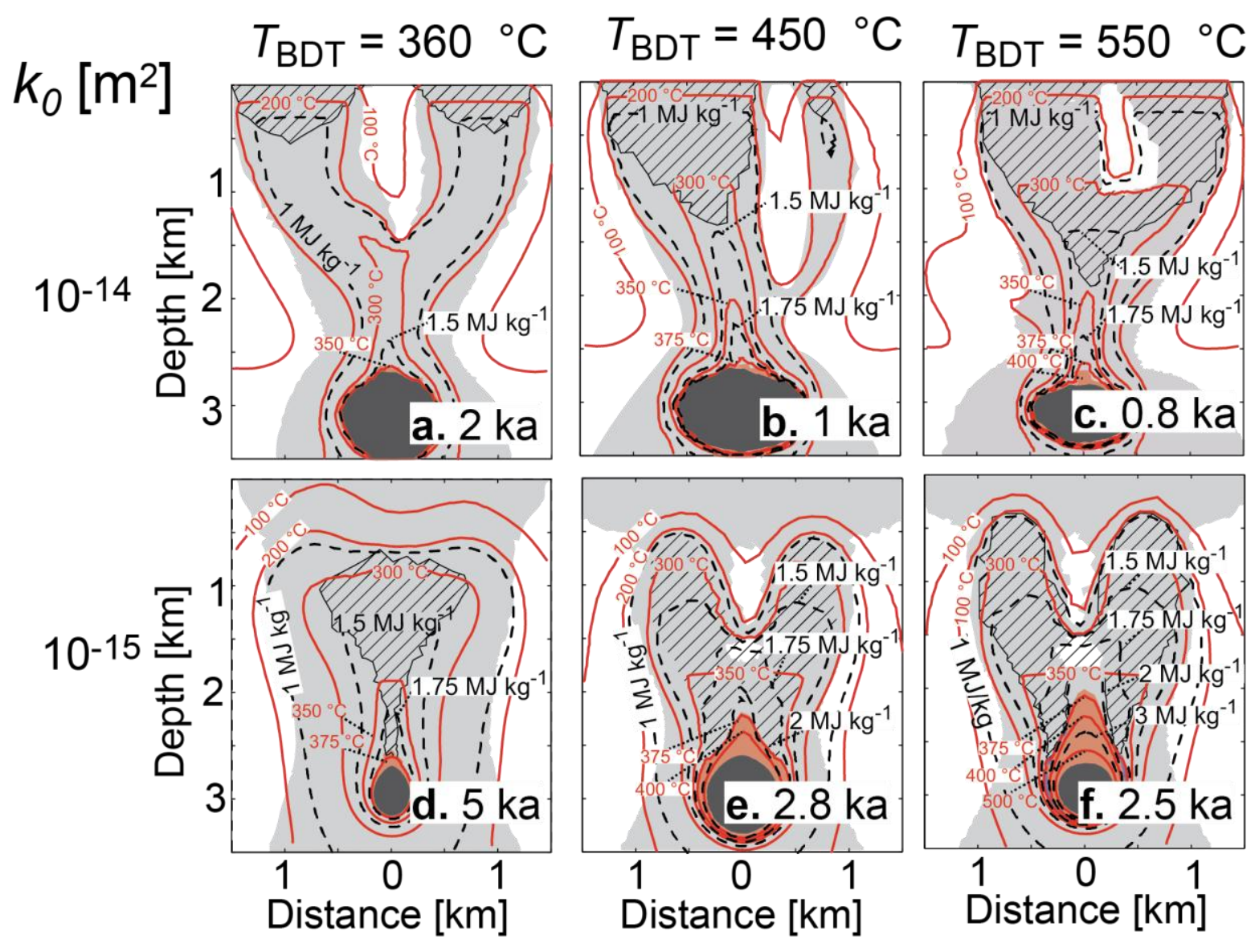

Figure 8. Effect of brittle-ductile transition temperature $\left(T_{B D T}\right)$ and host rock permeability $\left(k_{o}\right)$ on the thermal structure of high-enthalpy geothermal systems. Host rock permeability is varied from $10^{-14} \mathrm{~m}^{2}$ (a.-c.) to $10^{-15} \mathrm{~m}^{2}$ (d.-f.), and the brittle-ductile transition temperature is varied from $360{ }^{\circ} \mathrm{C}$ (a., d.), to $450{ }^{\circ} \mathrm{C}$ (b., e.), and $550{ }^{\circ} \mathrm{C}$ (c., f.). The emplacement depth is $3 \mathrm{~km}$. Fluid enthalpy contours are shown with dotted black lines. Supercritical geothermal resources (characterized by temperature and enthalpy greater than the critical values, $374{ }^{\circ} \mathrm{C}$ and 2.086 $\mathrm{MJ} \mathrm{kg}^{-1}$ ) are shown in red. Otherwise, coloring is the same as in Figure 4.

Increasing $T_{\mathrm{BDT}}$ from $360{ }^{\circ} \mathrm{C}$ to $450{ }^{\circ} \mathrm{C}$ in high permeability host rocks (comparing Fig. 8a-c) shifts the upper depth of the $1.5 \mathrm{MJ} \mathrm{kg}^{-1}$ isenthalp from $\sim 2.5 \mathrm{~km}$ to $\sim 1.5 \mathrm{~km}$ and causes the maximum depth of boiling in the system to increase from $\sim 0.5$ to $\sim 2 \mathrm{~km}$. Even if $T_{\mathrm{BDT}}$ is as high as $550{ }^{\circ} \mathrm{C}$, systems in high permeability host rocks do not develop large zones where fluid temperature and enthalpy exceed $400{ }^{\circ} \mathrm{C}$ and $2.5 \mathrm{MJ} \mathrm{kg}^{-1}$, respectively (Fig. 8c).

In contrast, when $T_{\mathrm{BDT}}$ is increased to 450 or $550{ }^{\circ} \mathrm{C}$ in intermediate permeability host rocks, systems develop boiling zones underlain by spatially extensive supercritical zones. Increasing $T_{\mathrm{BDT}}$ from $360{ }^{\circ} \mathrm{C}$ to $450{ }^{\circ} \mathrm{C}$ (comparing Fig. $8 \mathrm{~d}$ and e) shifts the upper depth of the $1.75 \mathrm{MJ} \mathrm{kg}^{-1}$ isoenthalp from $2 \mathrm{~km}$ to $1.5 \mathrm{~km}$ depth, and leads to the formation of an extensive supercritical resource above the intrusion with enthalpies $>2 \mathrm{MJ} \mathrm{kg}^{-1}$. The supercritical 
resource becomes larger if the $T_{\mathrm{BDT}}$ is increased to $550{ }^{\circ} \mathrm{C}$ (Fig. 8f), and temperatures and enthalpies can exceed $500{ }^{\circ} \mathrm{C}$ and $3 \mathrm{MJ} \mathrm{kg}^{-1}$. Although the size and thermal conditions of the supercritical resource in intermediate permeability systems are sensitive to the brittle-ductile transition temperature, increasing $T_{\mathrm{BDT}}$ from $450{ }^{\circ} \mathrm{C}$ to $550{ }^{\circ} \mathrm{C}$ in such systems results in a only slight increase in the enthalpy of upflow above $2 \mathrm{~km}$ depth or the dimensions of the boiling zone.

\section{Discussion}

\subsection{Thermal structure, depth of boiling and vapor fraction}

Host rock permeability, intrusion emplacement depth and the brittle-ductile transition temperature are the primary controls on the thermal structure of high-enthalpy systems. Plotting the results in a pressure-enthalpy ( $p$ - $h$ ) diagram (Fig. 9) explains the variations in geothermal system structure and depth of boiling and reveals that the upflow process is strongly non-isenthalpic. Systems display one of three general structures, with boiling restricted to the upper $\sim 1 \mathrm{~km}$, boiling from the surface down to the intrusion, or boiling underlain by hot supercritical fluid. Which structure a system shows is affected by the input of hot supercritical fluid ascending from the intrusion, the brittle-ductile transition temperature, and the degree to which the rising fluid mixes with lower temperature fluids circulating near the intrusion; mixing is enhanced by higher host rock permeability and deeper intrusion depth.

The enthalpy of ascending fluid decreases as a result of fluid mixing and heat loss to the surroundings. At the base of the upflow zone, directly above the intrusion, fluid enthalpy and temperature exceed critical values $\left(373.986{ }^{\circ} \mathrm{C},>2.086 \mathrm{MJ} \mathrm{kg}^{-1}\right)$ (Fig. 9, red area). Depending on how rapidly enthalpy decreases with depressurization, fluid passes from supercritical to two-phase conditions (hatched area), or directly to a single-phase liquid (white area to the left of the liquid limb of the two-phase field). The former case results in vertically 
extensive boiling zones, while in the latter case, the paths intersect the liquid limb of the twophase field at a lower pressure, producing boiling zones restricted to shallow depths $(<1 \mathrm{~km})$.
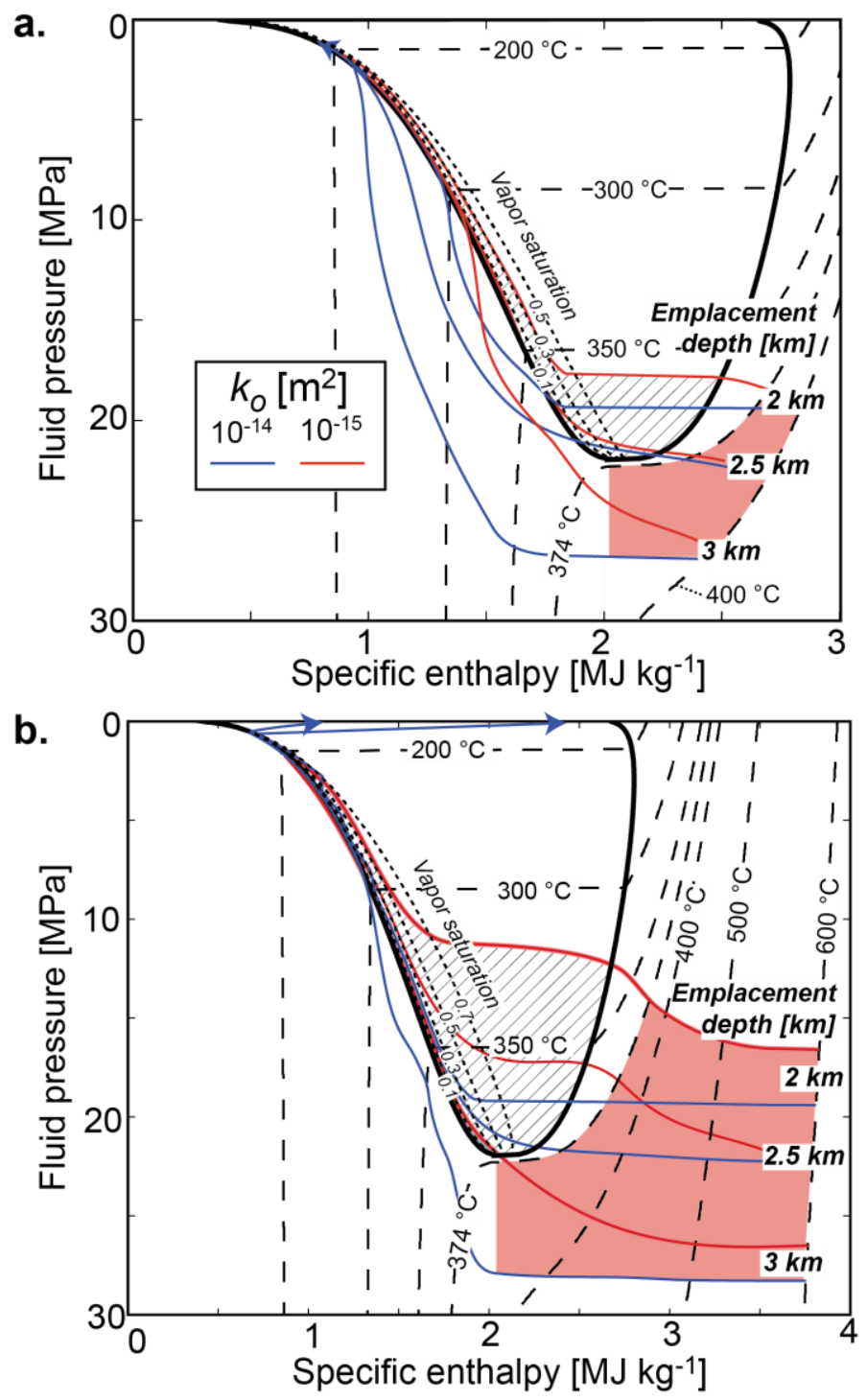

Figure 9. Fluid ascent paths in high-enthalpy systems with a brittle-ductile transition temperature of $360{ }^{\circ} \mathrm{C}$ (a.), and $550{ }^{\circ} \mathrm{C}$ (b.). Red lines represent thermal conditions along the center of the upflow for systems with a permeability of $10^{-15} \mathrm{~m}^{2}$, while blue lines show systems with a permeability of $10^{-14} \mathrm{~m}^{2}$. The hatched area is two-phase liquid and vapor, and red supercritical water. Isotherms are shown with thick dashed lines. Vapor volumetric saturation isolines are superimposed onto the two-phase field with fine dotted lines.

A rapid decrease in fluid enthalpy upon the onset of depressurization and fluid ascent produces shallow boiling zones restricted to $<1 \mathrm{~km}$ depth in systems with high permeability and $T_{B D T}=360{ }^{\circ} \mathrm{C}$ (blue paths, Fig. 9a). Fluid enthalpy decreases from supercritical to $<1.5$ $\mathrm{MJ} \mathrm{kg}{ }^{-1}$ over a pressure range of a few MPa. Within the liquid field, enthalpy decreases more gradually, corresponding to near-isothermal ascent. The paths intersect the two-phase field at 
a pressure depending on the intrusion depth, ranging from $\sim 10 \mathrm{MPa}(\sim 1 \mathrm{~km}$ depth $)$ for a system with an intrusion emplaced at $2 \mathrm{~km}$ to $3 \mathrm{MPa}$ for an intrusion at $3 \mathrm{~km}$. The depth of boiling decreases with increasing emplacement depth because a deeper intrusion means that ascending plumes must travel a greater distance from the intrusion to the surface, and are thus cooled more by mixing with surrounding cooler water and heat loss to the surroundings.

Vertically extensive boiling zones are seen in systems with $T_{B D T}=360{ }^{\circ} \mathrm{C}$ only when host rock permeability is intermediate and intrusion emplacement depth $\leq 2.5 \mathrm{~km}$ (red paths, Fig. 9a). This is because fluid enthalpy at the onset of depressurization decreases more gradually into the two-phase field. However, for the intermediate permeability system at 3 $\mathrm{km}$ emplacement depth, fluid pressure at the top of the intrusion is greater than the critical pressure of water (22.06 $\mathrm{MPa})$, preventing boiling in the lowermost part of the upflow plume. Enthalpy decreases into the liquid field before sub-critical pressures are reached, resulting in a depth of boiling near $10 \mathrm{MPa}(\sim 1 \mathrm{~km})$.

Vertically extensive boiling zones are observed in rocks with $T_{B D T}=550{ }^{\circ} \mathrm{C}$ even for high permeability systems driven by an intrusion at $\geq 2.5 \mathrm{~km}$ depth, and such boiling zones approach vapor-dominated conditions (characterized by a vapor volumetric saturation $>0.5$ ) when host rock permeability is intermediate (Fig. 9b). This is because higher $T_{B D T}$ increases the enthalpy of upflow plumes (Section 4.5). Within the boiling zones, fluid enthalpy as a function of pressure mirrors the $p$ - $h$ trend defined by the vapor-saturated liquid limb of the two-phase field. In high permeability systems, vapor saturation within the two-phase field is low $(<0.1)$, and bulk fluid enthalpy is essentially equal to that of vapor-saturated liquid as a function of pressure. The development of thermal conditions corresponding to boiling water with a small, nearly constant vapor saturation is consistent with geochemical evidence from liquid-dominated high-enthalpy geothermal fields (Scott et al., 2014). However, in intermediate permeability systems, fluid enthalpy and vapor saturation may be much higher. 
For an intermediate permeability system with an intrusion at $2 \mathrm{~km}$, the vapor saturation is $\sim 0.7$, approximating the assumed residual saturation of liquid where it is immobile. The existence of vapor-dominated conditions in geothermal systems is typically explained by fluid extraction, permeability barriers and/or topographic effects (White et al., 1971; Ingebritsen and Sorey, 1998). The observation from our simulations that vapor-dominated conditions develop in host rocks with a uniform, intermediate permeability suggests that the formation of these systems may also be controlled by the supply of fluid enthalpy at the base of the system, combined with overall mixing dynamics.

High $T_{B D T}$ increases the enthalpy of upflow zones by allowing advection of supercritical fluid, which is variably mixed with cooler waters during the process of ascent. The mechanisms of fluid enthalpy reduction include fluid mixing and heat loss from the fluid to surrounding rock. For systems at the main stage, temperatures in the upflow plume do not change greatly over time. Therefore, fluid mixing is the main mechanism of enthalpy reduction, and this is greatly dependent on host rock permeability (Scott et al., 2015). In high permeability rocks, the large fluxes of supercritical fluid are mixed with large quantities of recharging cooler liquid. In intermediate permeability systems mixing is more stagnant and the enthalpy of the upflow is significantly higher. Further, a deeper emplacement depth means a longer upflow path, and therefore a greater degree of fluid mixing and heat loss during fluid ascent.

\subsection{Number and spatial configuration of upflow plumes}

Geothermal systems can show one or more upflow plumes, and in the case of multiple plumes the lateral position of reservoirs and surface expressions may significantly differ from the location of the center of the intrusion, causing the system to display strong lateral and inverse temperature gradients at depth. The geologic controls, in combination with the temporal evolution of the system, determine the number and spacing of upflow plumes in 
geothermal systems. A high host rock permeability, intrusion emplacement depth $\geq 3 \mathrm{~km}$, and a more oblate intrusion geometry promote the development of multiple upflow plumes on the margins of the intrusion that are separated by a central zone with downward flowing liquid. In contrast, simulations with a shallow emplacement depth and intermediate permeability develop a single boiling plume over the center of the intrusion at the incipient stage that persists throughout the main and waning stages. For systems with multiple plumes, cooling of the intrusion from the sides inwards may cause the plumes to merge at depth, and boiling zones at the surface may not overly the highest temperatures at depth.

Multiple plumes and wider surface expressions, relative to the width of the intrusion, are characteristic of systems with a high host rock permeability, intrusion emplacement depth $\geq 3 \mathrm{~km}$, and an oblate intrusion geometry. In our simulations, while more than two plumes can develop during the early stages, two plumes on the margins of intrusion become dominant during the main stage. This is a consequence of the two-dimensional geometry, and a threedimensional system will behave differently and likely develop more plumes. As the plumes ascend, they spread laterally away from the center. This process is commonly referred to as 'outflow' among the geothermal community in describing areas where the fluid upflow has a strong lateral component (e.g. Cumming, 2009), and is a natural consequence of lateral pressure gradients that develop during the incipient and main stages (Fig. 3e). As a result of outflow, the width of the zone of surface expressions can exceed the initial width of the intrusion in high permeability systems.

Despite the asymmetric irregular mesh used in this study, most plume arrangements are quasi-symmetric about the center axis of the symmetric geometry. The degree of asymmetry increases with increased permeability, i.e. in advection-dominated systems (Fig. 5). Increasing $T_{B D T}$ has an additional effect on the asymmetric evolution, which is probably related to increasingly non-linear behavior of fluids near and above the critical point of pure water (Fig. 8). 
A stratovolcano above the center of the intrusion, or development of an impermeable caprock, would further promote outflow by increasing the hydrostatic pressure above the intrusion, thereby increasing the horizontal pressure gradient that drives lateral outflow (Hayba and Ingebritsen, 1997; Ratouis and Zarrouk, 2016). In high-permeability systems, this lateral outflow may also focus into preferred upflow at one flank of the volcano (Weis, 2015), rather than developing two symmetric upflow plumes as inferred by half-spaced models. A possible example of a geothermal system with multiple plumes associated to a single intrusion has not been previously described, a possible example of such a may be the Hengill system in Southwest-Iceland, which features two high-enthalpy geothermal fields separated by a central volcano underlain by relatively low temperatures (Gunnarson et al., 2010).

As the thermal structure of a system evolves over time, a system with initially multiple plumes develop a single plume at depth while retaining two separate surface expressions. In high permeability host rocks, merger of the two plumes on the margins into a central plume is observed once the width of the intrusion is less than $\sim 1 \mathrm{~km}$. Rather than ascending vertically into colder regions, the plume splits at around $\sim 1.5 \mathrm{~km}$ depth in order to follow paths heated by the early ascending plumes. As a result, the highest temperatures at depth do not underlie the high temperature, boiling areas at the surface. In high permeability systems, strong lateral outflow near the surface, combined with downward circulation of cold water at depth, creates temperature inversions on the sides of the upflow plumes in the incipient and main stages. The more sluggish outflow and downward flow in intermediate permeability systems produces broadly sub-vertical isotherms on the sides of centrally located upflow plumes.

In systems with a shallow emplacement depth and intermediate host rock permeability, plumes develop towards the center of the intrusion with a width close to that of the intrusion. Hence, the width of the upflow in these systems is close to constant, and the width of surface expressions does not greatly exceed the width of the impermeable intrusion, except during the late main stage and waning stage. 


\subsection{Geothermal system evolution and lifetime}

The rate of advective heat transfer by circulating hydrothermal fluids is the prime control on how fast an intrusion cools and is promoted by a higher host rock permeability, a shallower emplacement depth, and a higher brittle-ductile transition temperature. The capability of a system to advect heat also changes with time, as a result of evolution of the thermal structure of the intrusion and the hydraulic configuration related to plume breakthrough at the surface. Lower host rock permeability, greater emplacement depth and lower $T_{B D T}$ reduce the rate of advective heat transfer within a geothermal system, thereby increasing the likelihood that no main stage configuration is achieved. Temperatures in the hottest part of the intrusion decrease rapidly from supra-solidus to $<T_{B D T}$ in systems which display a main stage, but decrease gradually in systems without a main stage. In addition to

Temperature at center of intrusion

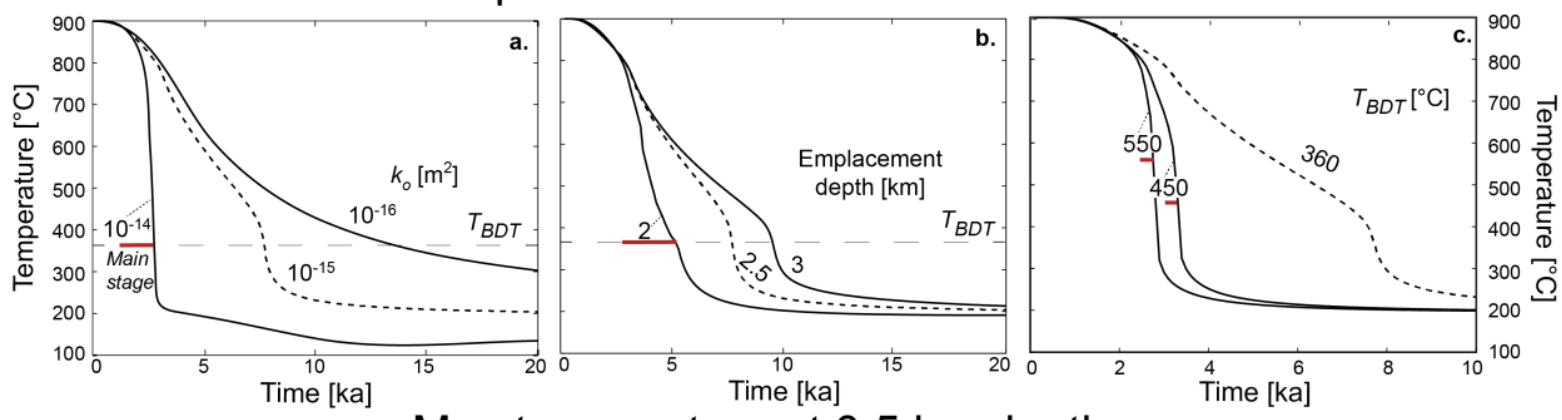

Max temperature at $0.5 \mathrm{~km}$ depth

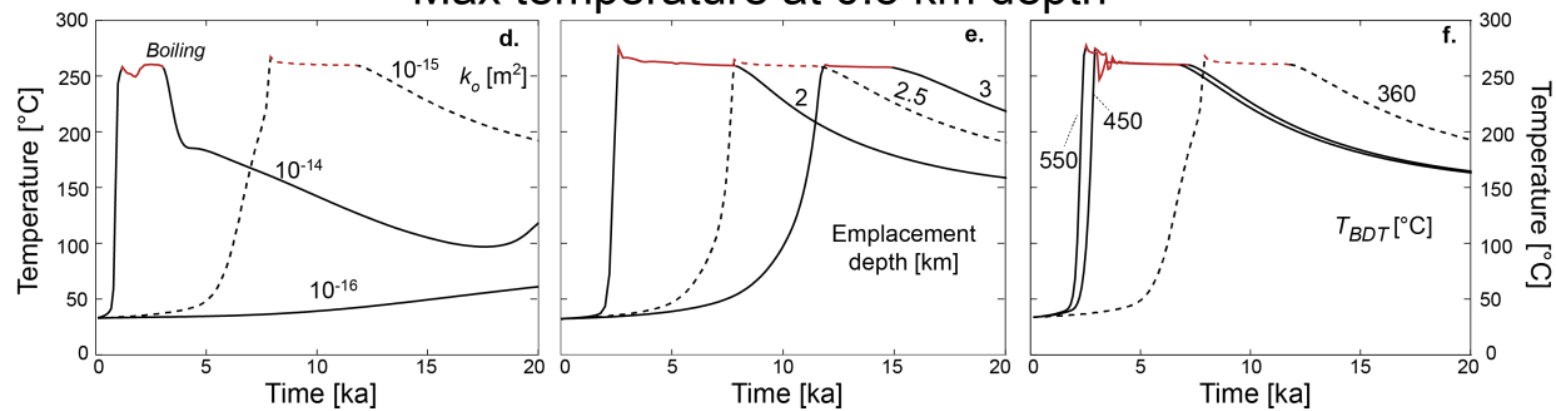

Figure 10. Fluid temperature at the center of the intrusion (a.-c.) and maximum temperature at $0.5 \mathrm{~km}$ depth (d.f.) as a function of time for simulations with: (a., d.) variable host rock permeability $\left(10^{-14}-10^{-16} \mathrm{~m}^{2}\right)$ and a constant emplacement depth $(2.5 \mathrm{~km})$ and brittle-ductile transition temperature $\left(360^{\circ} \mathrm{C}\right)$, (b. , e. $)$ variable emplacement depth (1.5-3.5 km) and a constant $k_{o}\left(10^{-15} \mathrm{~m}^{2}\right)$ and $T_{B D T}\left(360{ }^{\circ} \mathrm{C}\right)$, or $(\mathbf{c}$., f. $)$ variable $T_{B D T}(360$, 450 , or $\left.550{ }^{\circ} \mathrm{C}\right)$ and constant emplacement depth $(2.5 \mathrm{~km})$ and $k_{o}\left(10^{-15} \mathrm{~m}^{2}\right)$. The red bar in (a.-c.) indicates the duration of the main stage, when present. The red coloring of the line in (d.-f.) indicates boiling conditions. The dashed lines in all the figures show results from the same simulation. Note the different time scale of subfigure $\mathbf{c}$. 
causing more rapid cooling, higher host rock permeability results in a shorter duration of the boiling zones and relatively rapid near-surface temperature decrease during the waning stage. Intermediate permeability systems show a gradual reduction in temperatures at the surface during the waning stage.

Intrusions cool from magmatic temperatures to $<T_{B D T}$ more rapidly in systems with higher host rock permeability, shallower emplacement depth and higher $T_{B D T}$. Figure 10 considers the timescales of intrusion cooling (for a 2-dimensional intrusion initially $1.57 \mathrm{~km}^{2}$ in size, e.g. Figs. $4,5,8$ ) by showing the temperature at the center of the intrusion as a function of time, comparing the effect of host rock permeability (Fig. 10a), emplacement depth (Fig. 10b), and $T_{B D T}$ (Fig. 10c). In high permeability host rocks, temperature changes little for $2 \mathrm{ky}$, then decreases below $T_{B D T}$ within $1 \mathrm{ka}$ once the main stage is established (red bar). Likewise, a system with a host rock permeability of $10^{-15} \mathrm{~m}^{2}$ and an emplacement depth of $2 \mathrm{~km}$ show a main stage and a rapid temperature decrease (Figure 10b). Similarly, increasing $T_{B D T}$ from $360{ }^{\circ} \mathrm{C}$ to $\geq 450{ }^{\circ} \mathrm{C}$ causes a system with an intermediate host rock permeability and emplacement depth of $2.5 \mathrm{~km}$ to develop a short main stage and intrusions to cool more rapidly (Fig. 10c).

Analogous to Fig. 10a.-c., Fig. 10d.-f. shows maximum temperatures at $0.5 \mathrm{~km}$ depth as a function of time for variable host rock permeability, emplacement depth, and $T_{B D T}$. In the high permeability system, temperatures increase to $\sim 250{ }^{\circ} \mathrm{C}$ (boiling at $0.5 \mathrm{~km}$ ) over $<1 \mathrm{ky}$, remain high for $\sim 2.5 \mathrm{ky}$, then rapidly decline below $200{ }^{\circ} \mathrm{C}$ within $1 \mathrm{ky}$ (Fig. 10d). For intermediate permeability, temperatures increase more gradually to boiling temperatures, which remain there for $\sim 5 \mathrm{ky}$, and then slowly decrease. In the low permeability system, temperatures slowly increase but never exceed $100{ }^{\circ} \mathrm{C}$. Increasing emplacement depth from 2 to $3 \mathrm{~km}$ delays the onset of boiling by $\sim 10 \mathrm{ky}$ (Fig. 10e), but doesn't greatly impact the duration of boiling. Similarly, increasing $T_{B D T}$ from $360{ }^{\circ} \mathrm{C}$ to $450{ }^{\circ} \mathrm{C}$ or $550{ }^{\circ} \mathrm{C}$ causes boiling to occur $\sim 5$ ky earlier but doesn't greatly impact the duration of boiling or the pattern 
of temperature decay in the waning stages (Fig. 10f), which seems to be more controlled by host rock permeability.

Especially in intermediate permeability systems, the thermal conditions in the upper parts of a system $(<1 \mathrm{~km}$ depth) in the waning stage are quite similar to those of the main stage. Figures 4c, 5c, and $7 \mathrm{f}$ show that temperatures are lower throughout the first few thousand years of the waning stage than they are at the surface. This is because downflow of cold fluid is directed towards the deep, high-temperature regions, while heat loss from the surface is relatively slow. Thus, temperature inversions below $\sim 0.5-1 \mathrm{~km}$ depth dominate the early waning stage, which is spent slowly cooling from the bottom up.

\subsection{Implications for geothermal exploration}

General. Our simulations replicate characteristic thermal structures displayed in real systems in different geological environments, and illustrate how these may relate spatially to the heat source. Furthermore, they track the controls on boiling zones, and elucidate how these change over the long-term evolution of high-enthalpy geothermal systems. Using inferences from these models, it may be possible to use measured field properties such as temperature, pressure and fluid enthalpy to make generic inferences about the current state of the system, including geological, hydraulic, and thermal reservoir conditions at depth.

For example, the presence of boiling conditions at $>1 \mathrm{~km}$ or $>300{ }^{\circ} \mathrm{C}$ is a key indicator of a system with intermediate host rock permeability and an intrusion depth $\leq 2.5 \mathrm{~km}$ in its main stage. Alternatively, if there is boiling at $>1 \mathrm{~km}$ and system-scale host rock permeability is known to be $\geq 10^{-14} \mathrm{~m}^{2}$, there must be a shallow intrusion and/or a high brittleductile transition temperature, the latter of which would primarily be controlled by the type of host rock. The vapor fraction (enthalpy) of boiling reservoirs allows estimation of the

intrusion depth and $T_{B D T}$, and therefore the possible presence of underlying supercritical geothermal resources nearer the intrusion. The number of upflow zones and their locations 
relative to the intrusion may change vertically and temporally, and systems with a high host rock permeability and intrusion depth $\geq 2.5 \mathrm{~km}$ characteristically display multiple upflow plumes near the surface that may join at depth. The models suggest that horizontal and vertical pressure and temperature gradients may potentially be used to identify the heat source and the optimal targets for drilling. However, some geothermal systems appearing to be at the main stage in an area that is volcanically active for $>10^{4}$ years (Arnórsson, 1995; Houghton et al., 1995) may actually be related to a long waning stage lasting $>10^{3}$ years during which surface conditions are similar to the main stage.

Characterizing reservoir permeability and nature of heat source. The simulations reveal characteristic temperature/depth profiles which allow a first-order diagnosis of host rock permeability, intrusion depth and brittle-ductile transition temperature. Figure 11 shows temperature/depth profiles along the upflow path during the main stage for same simulations as considered in Figure 9. Systems with a low brittle-ductile transition temperature of $360{ }^{\circ} \mathrm{C}$ (Fig. 11a) and high host rock permeability (blue lines) follow the boiling point curve to a maximum depth of $0.5-1 \mathrm{~km}$, with the maximum depth of boiling decreasing as intrusion depth increases from 2-3 km. Temperatures in intermediate permeability systems (red lines) with intrusion depth $\leq 2.5 \mathrm{~km}$ follow the boiling point with depth curve over the entire depth range, but follow the boiling curve only above $\sim 1 \mathrm{~km}$ for an intrusion depth of $3 \mathrm{~km}$. Temperatures are slightly elevated relative to the boiling point with depth curve (calculated for a column of pure vapor-saturated liquid) because fluid pressures are higher than hot hydrostatic during the main stage (Fig. 3e). Measured fluid pressure gradients exceeding hot hydrostatic values are commonly found in high-enthalpy geothermal systems (Donaldson et al, 1983). Elevated temperatures relative to the boiling point curve can also be produced during the incipient stage due to cold hydrostatic pressure gradients at the surface. 

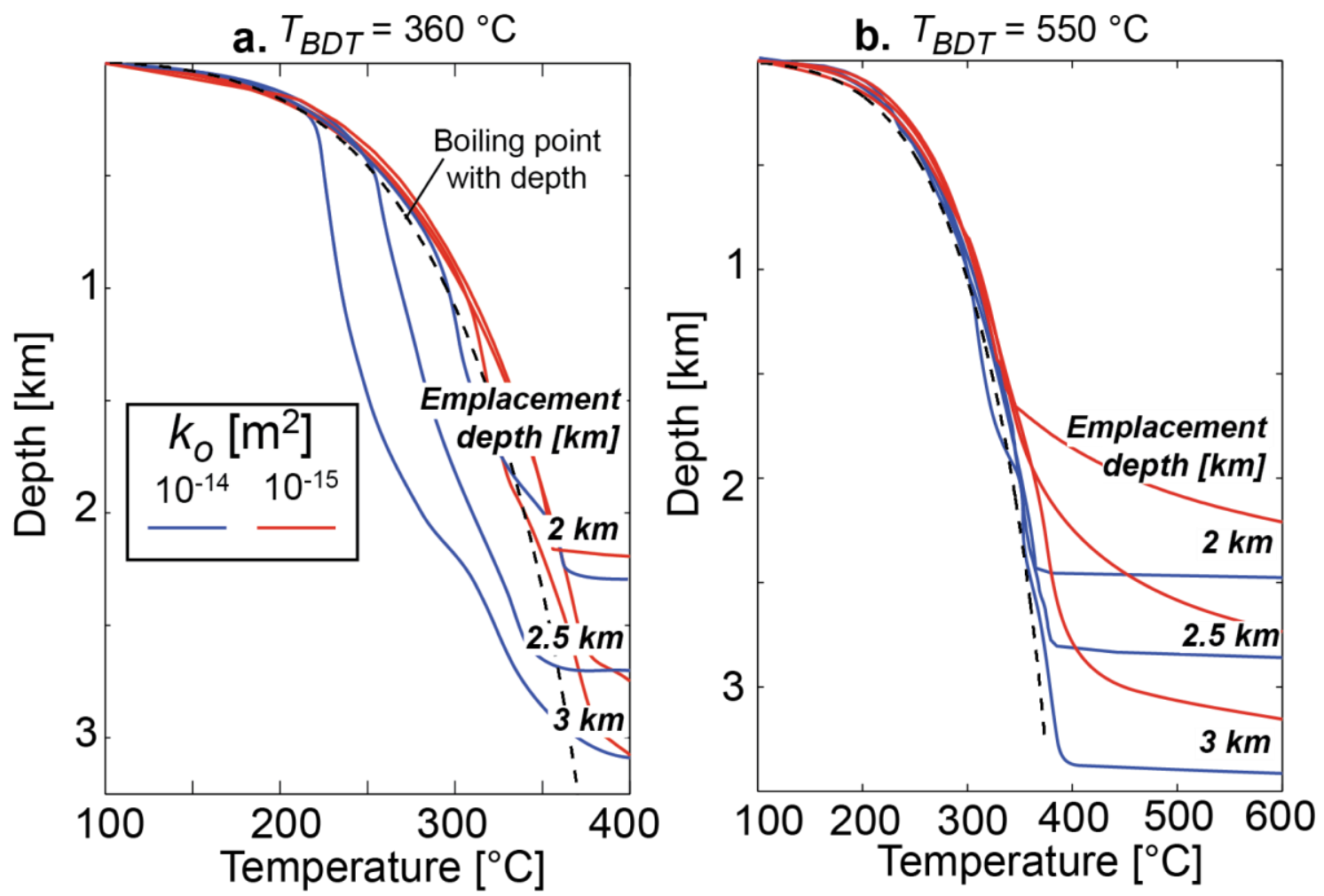

Figure 11. Characteristic temperature-depth profiles resulting from variation of host rock permeability, emplacement depth, and brittle-ductile transition temperature of $360{ }^{\circ} \mathrm{C}$ (a.) or $550{ }^{\circ} \mathrm{C}(\mathbf{b}$.). Red lines represent thermal conditions along the upflow path for systems with a permeability of $10^{-15} \mathrm{~m}^{2}$, while blue lines show systems with a permeability of $10^{-14} \mathrm{~m}^{2}$. Paths are extracted for the same simulations as shown in Figure 9.

Potential for and location of supercritical resources at depth. Rocks with a brittleductile transition temperature of $550{ }^{\circ} \mathrm{C}$ allow the development of vertically extensive boiling zones in high permeability systems and deep supercritical zones in intermediate permeability systems (Fig. 11b). High $T_{B D T}$ increases the mass of fluid advecting at supercritical conditions. In high permeability systems, the dilution of supercritical fluid ascending from the intrusion with large quantities of circulating liquid causes a rapid decrease in fluid temperature from $T_{B D T}$ to boiling temperatures. Less intense mixing in intermediate permeability systems leads to vertically extensive supercritical zones above the intrusion (Scott et al., 2015). Within the supercritical zones for systems with an intrusion at 2 or 2.5 $\mathrm{km}$, temperatures gradually increase from $374{ }^{\circ} \mathrm{C}$ to $T_{B D T}$ with increasing proximity to the intrusion. For an intrusion at $3 \mathrm{~km}$, temperatures are nearly isothermal within the supercritical zone $\left(400{ }^{\circ} \mathrm{C}\right)$ and rapidly increase in the vicinity of the intrusion. For systems with high $T_{B D T}$, 
fluid enthalpy (Fig. 9b), rather than temperature, is a better gauge of the geologic controls and a better predictor of supercritical geothermal resources.

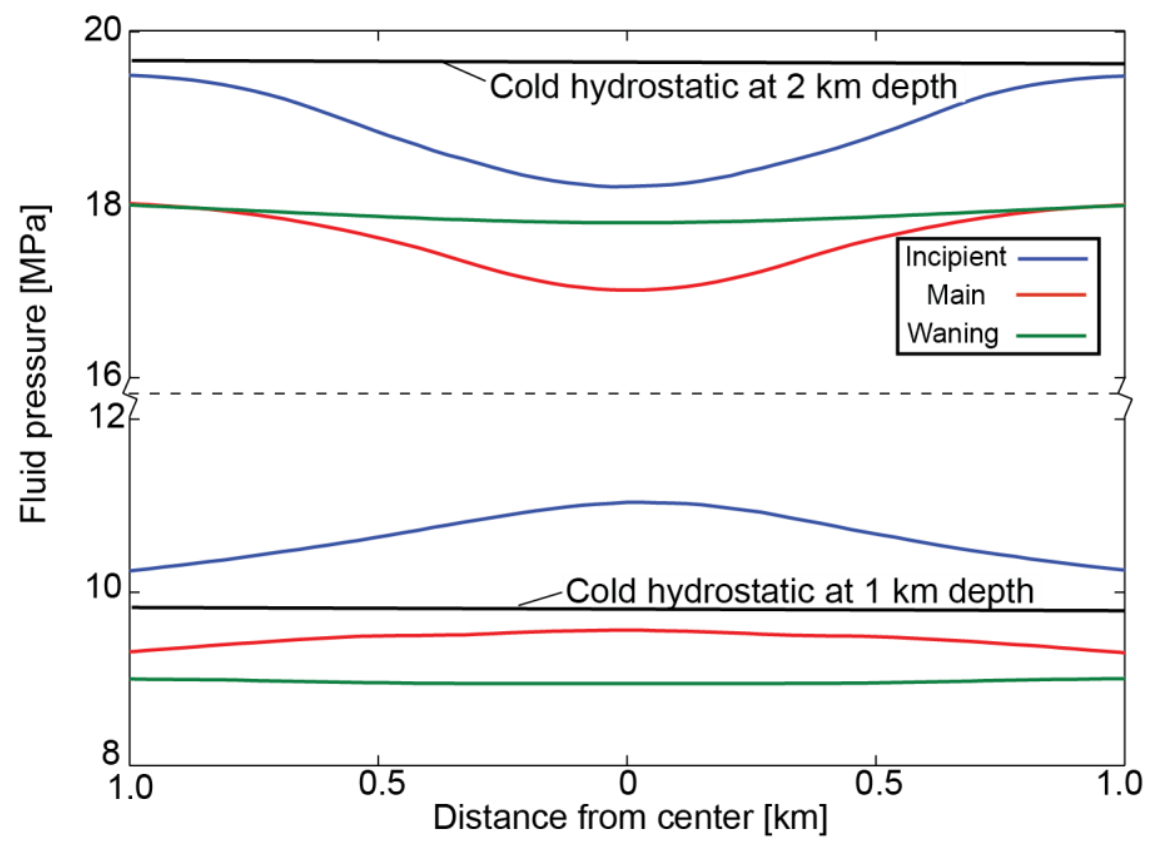

Figure 12. Lateral pressure profiles at 1 (bottom) and $2 \mathrm{~km}$ (top) depth during the incipient (blue), main (red) and waning (red) stage of the evolution of a system with a host rock permeability of $10^{-15} \mathrm{~m}^{2}$, emplacement depth $2.5 \mathrm{~km}$, and $T_{B D T} 360{ }^{\circ} \mathrm{C}$.

Identifying active heat sources. The presence and location of an active heat source may be detectable from lateral pressure gradients. Figure 12 compares lateral pressure gradients at 1 and $2 \mathrm{~km}$ depth in an intermediate permeability system. As discussed in Section 4.1.2 (Fig. 3e), fluid pressure at $1 \mathrm{~km}$ depth increases towards the center of the upflow plume during the incipient and main stages. However, at $2 \mathrm{~km}$ depth, fluid pressure decreases towards the center of the upflow plume during the incipient and main stages. The vertically extensive and vapor-rich boiling zones have a lower density, and therefore exert a lower hydrostatic pressure gradient, relative to the cold, dense liquid on the margins of the system. The horizontal pressure gradient drives flow of cold fluid from the margins towards the intrusion. In real systems fluid pressure will also be affected by permeability heterogeneities, such as a cap rock and high permeability faults, as well as by surface topography. 
Identifying the natural state of a system; indications for blind resources. Vertical temperature inversions may also aid in identification of the lateral position of the heat source and the hottest parts of the upflow. Geothermal wells that exhibit temperature inversions are relatively common in high-enthalpy systems (Bödvarsson, 1973; Grant and Bixley, 2011). In high permeability systems at the main stages, lateral outflow near the surface, combined with vigorous inflow of meteoric water towards the intrusion gives rise to temperature inversions below $1.5 \mathrm{~km}$ depth towards the sides of the intrusion (as seen in i.e., Fig. 8a.-c.). In intermediate permeability systems, temperature inversions during the main stage are not as strong, as less vigorous inflow tends to produce more widely spaced isotherms that are nearly symmetrical around the intrusion at depth. Of course, an alternative explanation for widespread temperature inversions below $1-2 \mathrm{~km}$ is a system at the waning stage.

Although most active geothermal systems are probably considered to be at the main stage, given the long lifespan of volcanic terranes relative to the cooling of individual intrusions, the models highlight key aspects of high-enthalpy systems at the incipient or waning stage. Our models assume instantaneous emplacement of an intrusion in relatively cold crust, and therefore these systems have an incipient stage where convection must work against colder overlying groundwaters. As a result of the higher hydrostatic pressures during the incipient stages, the temperature and enthalpy of 'blind' resources at a given depth is greater than during the main stage (Fig. 3d). Even high-enthalpy systems at the waning stage may be suitable for exploitation if boiling extends to depths of $\sim 0.5 \mathrm{~km}$. However, in systems at the waning stage, the dynamics of fluid downflow will be different, since there is no longer an intrusion to heat the recharging fluid, and systems may cool much more rapidly in response to fluid injection. This discussion highlights the importance of considering the time-dependent evolution of these systems during geothermal exploration and field management.

\section{Conclusions}


The numerical simulations of fluid flow around magmatic intrusions presented in this study elucidate key features of the natural thermal and hydraulic structures of high-enthalpy systems. We highlight key aspects of the systems character during the incipient, main and waning stages.

- Systems with high host rock permeability generally display near-isothermal upflow of liquid in their deeper parts and boiling at depths $\leq 1 \mathrm{~km}$, while intermediate permeability systems may develop vertically extensive boiling zones extending from the surface to the top of the intrusion.

- Intrusion emplacement depth is a further control on the extent of boiling zones, as intermediate permeability systems driven by an intrusion at $\geq 3 \mathrm{~km}$ depth only show boiling above $1 \mathrm{~km}$ depth.

- Systems with an emplacement depth $\geq 3 \mathrm{~km}$ and high permeability may develop multiple upflow plumes in the upper parts of a geothermal system in response to a single intrusive body. Although the width and shape of the intrusion influences the number and spacing of upflow zones, the deep thermal structure is nearly independent of intrusion geometry.

- If the host rock can sustain brittle deformation to temperatures $\geq 450{ }^{\circ} \mathrm{C}$, high permeability systems may develop vertically extensive boiling zones, and intermediate permeability systems develop extensive zones of supercritical water near the intrusion.

- The simulations reveal that systems develop characteristic lateral and vertical gradients in pressure, temperature and enthalpy relative to the intrusive heat source, potentially enabling better estimation of the lateral position of the underlying heat source.

- Higher-permeability and higher-enthalpy geothermal systems have an increased tendency towards asymmetric plume developments. 


\section{Acknowledgements}

This study was funded by the Swiss National Science Foundation (CRSII2_141843/1, Sinergia COTHERM).

\section{References}

Aradóttir, E.S.P., Sonnenthal, E.L., Bjórnsson, G., Jónsson, H., 2012. Multidimensional reactive transport modeling of $\mathrm{CO}_{2}$ mineral sequestration in basalts at the Hellisheidi geothermal field, Iceland. International Journal of Greenhouse Gas Control 9, 24-40.

Arnórsson, S., 1995. Geothermal systems in Iceland: Structure and conceptual models-I. High-temperature areas. Geothermics 24, 561-602.

Arnórsson, S., Stefansson, A., Bjarnason, J.Ö., 2007. Fluid-Fluid Interactions in Geothermal Systems. Rev. Mineral. Geochemistry 65, 259-312. doi:10.2138/rmg.2007.65.9

Axelsson, G., 2010. Sustainable geothermal utilization - Case histories; definitions; research issues and modelling. Geothermics 39, 283-291. doi:10.1016/j.geothermics.2010.08.001

Banwell, C.J., 1963. Thermal energy from the Earth's crust, New Zealand Journal of Geology and Geophysics 6:1, 52-59, doi:10.1080/00288306.1963.10420089

Bödvarsson, G.S., 1961. Physical Characteristics of Natural Heat Resources in Iceland. Jökull $11,29-38$.

Bödvarsson, G.S., 1969. Evaluation of Geothermal Prospects and the Objectives of Geothermal Exporation. Geoexploration 8, 7-17.

Bödvarsson, G.S., 1973. Temperature Inversions in Geothermal Systems. Geoexploration 11, 141-149.

Bödvarsson, G.S., Pruess, K., Lippmann, M., 1986. Modeling of Geothermal Systems. Journal of Petroleum Technology 38:9, 1007-21

Björnsson, G., Bödvarsson, G., 1990. A Survey of Geothermal Reservoir Properties. Geothermics 19, 17-27.

Burchardt, S., Gudmundsson, A. The infrastructure of the Geitafell Volcano, Southeast Iceland. In: Thordarson, T., Self., S., Larsen, G., Rowland, S.K., Hoskuldsson. A. (eds) Studies in Volcanology: The Legacy of George Walker. Special Publications of IAVEI, 2. Geological Society, London, 349-369

Cathles, L., Erendi, A., Barrie, T., 1997. How long can a hydrothermal system be sustained by a single intrusive event? Econ. Geol. 92, 766-771. 
Cathles, L.M., 1993. A Capless $350^{\circ} \mathrm{C}$ Flow Zone Model to Explain Megaplumes, Salinity Variations, and High-Temperature Veins in Ridge Axis Hydrothermal Systems. Econ. Geol. 88, 1977-1988.

Cathles, L.M., 1977. An Analysis of the Cooling of Intrusives by Ground-Water Convection which Includes Boiling. Econ. Geol. 72, 804-826.

Coumou, D., Driesner, T., Heinrich, C. A., 2008. Heat transport at boiling, near-critical conditions. Geofluids 8, 208-215. doi:10.1111/j.1468-8123.2008.00218.x

Croucher, A.E., O'Sullivan, M.J., 2008. Application of the Computer Code TOUGH2 to the Simulation of Supercritical Conditions in Geothermal Systems, Geothermics 37, 662-634.

Cumming, W., 2009. Geothermal Resource Conceptual Models Using Surface Exploration Data. in: Proceedings, Thirty-Fourth Workshop on Geothermal Reservoir Engineering. Stanford University, Stanford, California.

Curewitz, D., Karson, J.A., 1997. Structural settings of hydrothermal outflow: Fracture permeability maintained by fault propagation and interaction. Journal of Volcanology and Geothermal Research 79, 149-168

Donaldson, I., Grant, M., Bixley, P., 1983. Nonstatic Reservoirs: The Natural State of the Geothermal Reservoir. J. Pet. Technol. 35, 189-194.

Driesner, T., Geiger, S. 2007. Numerical simulation of multiphase fluid flow in hydrothermal systems. Reviews in Mineralogy and Geochemistry 65, 187-212.

Finsterle, S., 2007. iTOUGH2 User's Guide. LBNL-40040. Lawrence Berkeley National Laboratory, Berkeley, California.

Fournier, R., 1991. The Transition from Hydrostatic to Greater than Hydrostatic Fluid Pressure in Presently Active Continental Hydrothermal Systems in Crystalline Rock. Geophys. Res. Lett. 18, 955-958.

Fournier, R., 1999. Hydrothermal Processes Related to Movement of Fluid From Plastic into Brittle Rock in the Magmatic-Epithermal Environment. Econ. Geol. 94, 1193-1212.

Franzson, H., 1998. Reservoir Geology of the Nesjavellir High-Temperature Field in SWIceland. Proc. 19th Annu. PNOC-EDC Geotherm. Conf. 13-20.

Fridleifsson, I.B., 1978. Applied volcanology in geothermal exploration in Iceland. Pure Appl. Geophys. 117, 242-252.

Grant, M. A. and Bixley, P. F. (2011) Geothermal Reservoir Engineering - Second Edition. Academic Press, Burlington, Vermont.

Grant, M. A. and Sorey, M.L., 1979. The compressibility and hydraulic diffusivity of a watersteam flow. Water Resources Research 15, 684-686 
Gudmundsson, A., 2012. Magma chambers: Formation, local stresses, excess pressures, and compartments. J. Volcanol. Geotherm. Res. 237-238, 19-41.

doi:10.1016/j.jvolgeores.2012.05.015

Gunnarsson, G., Aradóttir, E.S.P., 2014. The Deep Roots of Geothermal Systems in Volcanic Areas: Boundary Conditions and Heat Sources in Reservoir Modeling. Transp. Porous Media 108, 43-59. doi:10.1007/s11242-014-0328-1

Gunnarsson, G., Arnaldsson, A., Oddsdóttir, A.L., 2010. Model Simulations of the Hengill Area, Southwestern Iceland. Transp. Porous Media 90, 3-22. doi:10.1007/s11242-0109629-1

Haar, L., Gallagher, J.S., Kell, G. 1984. NBS/NRC Steam Tables. Hemisphere Publishing. Washington, D.C.

Hayba, D.O., Ingebritsen, S.E., 1997. Multiphase groundwater flow near cooling plutons. J. Geophys. Res. 102, 12235. doi:10.1029/97JB00552

Henley, R.W., Ellis, a. J., 1983. Geothermal systems ancient and modern: a geochemical review. Earth-Science Rev. 19, 1-50. doi:10.1016/0012-8252(83)90075-2

Hurwitz, S., Kipp, K.L., Ingebritsen, S.E., Reid, M.E., 2003. Groundwater flow, heat transport, and water table position within volcanic edifices: Implications for volcanic processes in the Cascade Range. J. Geophys. Res. 108, 2557.

Ingebritsen, S., Sanford, W., Neuzil, C., 2006. Groundwater in Geologic Processes. Second Edition. Cambridge University Press, New York

Ingebritsen, S., Sorey, M., 1988. Vapor-Dominated Zones Within Hydrothermal Systems: Evolution and Natural State. J. Geophys. Res. 93, 13,635-13,655.

Ingebritsen, S.E., Geiger, S., Hurwitz, S., Driesner, T., 2010. Numerical Simulation of Magmatic Hydrothermal Systems. Rev. Geophys. 48, 1-33.

Ingebritsen, S.E., Manning, C.E., 1999. Geological implications of a permeability-depth curve for the continental crust. Geology 27, 1107-1110.

Lees, J.M., 2007. Seismic tomography of magmatic systems. J. Volcanol. Geotherm. Res. 167, 37-56. doi:10.1016/j.jvolgeores.2007.06.008

Magnusdóttir, L., Finsterle, S., 2015. An iTOUGH2 equation-of-state module for modeling supercritical conditions in geothermal reservoirs, Geothermics 57, 8-17.

Manning, C.E., Ingebritsen, S.E., 1999. Permeability of the continental crust: Implications of geothermal data and metamorphic systems. Rev. Geophys. 37, 127-150.

Marsh, B., 1989. Magma Chambers. Annu. Rev. Earth Planet. Sci. 17, 439-474. doi:10.1146/annurev.earth.17.1.439

Norton, D., Knight, J., 1977. Transport Phenomena in Hydrothermal Systems: Cooling Plutons. Am. J. Sci. 277, 937-981. 
Norton, D., Taylor, H., 1979. Quantitative Simulation of the Hydrothermal Systems of Crystallizing Magmas on the Basis of Transport Theory and Oxygen Isotope Data: An analysis of the Skaergaard Intrusion. J. Petrol. 20, 421-486.

O’Sullivan, M.J., Pruess, K., Lippmann, M.J., 2001. State of the art of geothermal reservoir simulation. Geothermics 30, 395-429. doi:10.1016/S0375-6505(01)00005-0

O'Sullivan, M.J., Yeh, A., Mannington, W.I., 2009. A history of numerical modelling of the Wairakei geothermal field. Geothermics 38, 155-168, doi:10.1016/j.geothermics.2008.12.001

Pritchett, J.W., 2007. Goehtermal reservoir engineering in the United States since the 1980s. Geothermal resources Council Transactions 31, 31-37

Pruess, K., Oldenburg, C., Moridis, G., 1999. TOUGH2 User's Guide, Version 2.0. LBNL43134. Lawrence Berkeley National Laboratory. Berkeley, California.

Romagnoli, R., Arias, A., Barelli, A., Cei, M., Casini, M. 2010. An updated numerical model of the Lardarello-Travale geothermal system. Geothermics 39, 292-313.

Scott, S., Gunnarsson, I., Arnórsson, S., Stefánsson, A., 2014. Gas chemistry, boiling and phase segregation in a geothermal system, Hellisheidi, Iceland. Geochim. Cosmochim. Acta 124, 170-189. doi:10.1016/j.gca.2013.09.027

Scott, S., Driesner, T., Weis, P., 2015. Geologic controls on supercritical geothermal resources above magmatic intrusions. Nature Communications 6:7837

Sibbett, B.S., 1988. Size, depth and related structures of intrusions under stratovolcanoes and associated geothermal systems. Earth-Science Rev. 25, 291-309.

Stefánsson, V., Björnsson, S., 1982. Physical aspects of hydrothermal systems. In: Continental and Oceanic Rifts (ed. G. Pálmason), American Geophysical Union, Washington, D.C., doi: 10.1029/GD008p0123

Straus, J.M., Schubert, G., 1981. One-Dimensional Model of Vapor-Dominated Systems. J. Geophys. Res. 86, 9433-9438.

Ratouis, T.M.P., Zarrouk, S.J., 2016. Factors controlling large-scale hydrodynamic convection in the Taupo Volcanic Zone (TVZ), New Zealand, Geothermics 59, 236-251, doi:10.1016/j.geothermics.2015.09.003.

Violay, M., Gibert, B., Mainprice, D., Burg, J.-P., 2015. Brittle versus ductile deformation as the main control of the deep fluid circulation in oceanic crust. Geophys. Res. Lett. 42, doi:10.1002/2015GL063437. doi:10.1002/2015GL063437.Received

Violay, M., Gibert, B., Mainprice, D., Evans, B., Dautria, J.-M., Azais, P., Pezard, P., 2012. An experimental study of the brittle-ductile transition of basalt at oceanic crust pressure and temperature conditions. J. Geophys. Res. Solid Earth 117, n/a-n/a. doi:10.1029/2011JB008884 
Weis, P., 2015. The dynamic interplay between saline fluid flow and rock permeability in magmatic-hydrothermal systems. Geofluids 15, 350-371. doi:10.1111/gfl.12100

Weis, P., Driesner, T., Coumou, D., Geiger, S., 2014. Hydrothermal, multiphase convection of $\mathrm{H}_{2} \mathrm{O}-\mathrm{NaCl}$ fluids from ambient to magmatic temperatures: a new numerical scheme and benchmarks for code comparison. Geofluids 14, 347-371. doi:10.1111/gfl.12080

White, B.R., Chambefort, I., 2015. Geothermal development history of the Taupo Volcanic Zone. Geothermics. (in press). doi:10.1016/j.geothermics.2015.10.001

White, D., 1957. Thermal waters of volcanic origin. Geol. Soc. Am. Bull. 68, 1637-1658. doi:10.1130/0016-7606(1957)68

White, D., 1965. Geothermal energy. U.S. Geological Survey Circular 519, 17 p.

White, D., 1967. Some principles of geyser activity, mainly from Steamboat Springs, Nevada. American Journal of Science. 265, 641-684

White, D., Muffler, L., Truesdell, A., 1971. Vapor-dominated hydrothermal systems compared with hot-water systems. Econ. Geol. 66, 75-97.

Woods, A.M., 1999. Liquid and vapor flow in superheated rock. Annual Review of Fluid Mechanics 31:171-199 doi: 10.1146/annurev.fluid.31.1.171

\section{Appendices}

\section{Appendix A: Governing equation and computational method}

This study was performed using the Complex Systems Modeling Platform (CSMP++) (Weis et al., 2014). The governing equations of multi-phase mass and energy conservation are solved using a pressure-enthalpy-based formulation in a Control Volume-Finite Element Method numerical scheme using a continuum porous media approach. Phase velocities were obtained using an extend two-phase form of Darcy's law:

$$
\boldsymbol{v}_{i}=-k \frac{k_{r, i}}{\mu_{i}}\left(\nabla p-\rho_{i} \boldsymbol{g}\right) \quad i=1, \mathrm{v}
$$

where $k$ is the permeability $\left(\mathrm{m}^{2}\right), k_{r, i}$ is the relative permeability of phase $i(-), \mu_{i}$ is the dynamic viscosity, $\nabla p$ is the pressure gradient, $\rho_{i}$ is the phase density, and $\mathbf{g}$ is the gravitational acceleration vector. A linear relative permeability model with a liquid residual saturation of 0.3 and vapor residual saturation of zero is adopted (Hayba and Ingebritsen, 1997).

Conservation of fluid mass is given by:

$$
\frac{\partial\left(\varphi\left(S_{l} \rho_{l}+S_{v} \rho_{v}\right)\right)}{\partial t}=-\nabla \cdot\left(\mathbf{v}_{l} \rho_{l}\right)-\nabla \cdot\left(\mathbf{v}_{v} \rho_{v}\right)+Q_{H 2 O}
$$

where $S_{i}$ is the volumetric saturation of each phase and and $Q_{H 2 O}$ a fluid source term. Energy conservation accounts for conduction of heat in the rock and advection of enthalpy by fluid: 


$$
\frac{\partial\left((1-\varphi) \rho_{r} h_{r}+\varphi\left(S_{l} \rho_{l} h_{l}+S_{v} \rho_{v} h_{v}\right)\right)}{\partial t}=\nabla \cdot(K \nabla T)-\nabla \cdot\left(\mathbf{v}_{l} \rho_{l} h_{l}\right)-\nabla \cdot\left(\boldsymbol{v}_{v} \rho_{v} h_{v}\right)+Q_{e}
$$

with $K$ as the thermal conductivity of the rock and fluid medium and $Q_{e}$ as an energy source term. Thermal equilibrium between the rock and fluid at a given node in the mesh and at each time step is ensured by interating temperature at a constant pressure and redistributing the total enthalpy between rock and fluid according to their thermodynamic properties until they each have the same temperature.

The pressure equation is solved decoupled from the energy equation, and can be derived from substituting the mass conservation equation into Darcy's law:

$$
\rho_{f}\left[\varphi \beta_{f}+(1-\varphi) \beta_{r}\right] \frac{\partial p}{\partial t}=\nabla \cdot\left[\boldsymbol{k}\left(\frac{k_{r, l} \rho_{l}}{\mu_{l}}+\frac{k_{r, v} \rho_{v}}{\mu_{v}}\right) \nabla p\right]+\boldsymbol{k}\left(\frac{k_{r, l} \rho_{l}^{2}}{\mu_{l}}+\frac{k_{r, v} \rho_{v}^{2}}{\mu_{v}}\right) \boldsymbol{g} \nabla z+Q_{p}
$$

with $\beta$ denoting the compressibility of the fluid or rock $\left(\beta_{f} \gg \beta_{r}\right)$. Two-phase compressibility, which is several orders of magnitude higher than pure liquid or vapor compressibility, is calculated using the approximation of Grant and Sorey (1979). Thermal equilibration alters the densities and saturations of the fluid phases and potentially can cause large volume mismatches if a phase change occurs during equilibration. The resulting volume mismatch between the thermodynamic fluid density and the mass stored in the pore volume is fed as a source term $Q_{p}$.

\section{Appendix B: Temperature-dependent permeability model}

The temperature dependent permeability model is based on the formulation of Hayba and Ingebritsen (1997) but the formulation has been generalized so that the brittle-ductile transition temperature conditions can be changed.

$$
k=\left\{\begin{array}{cc}
\log \left(k_{0}\right), & T<T_{B D T} \\
\log \left(k_{0}\right)\left(T_{\text {ductile }}-T\right)+\log \left(k_{\text {ductile }}\right)\left(\frac{T-T_{B D T}}{T_{\text {ductile }}-T_{B D T}}\right), & T_{B D T}<T<T_{\text {ductile }} \\
\log \left(k_{\text {ductile }}\right)\left(T_{\min }-T\right)+\log \left(k_{\min }\right)\left(\frac{T-T_{\text {ductile }}}{T_{\text {min }}-T_{\text {ductile }}}\right), & T_{\text {ductile }}<T<T_{\text {min }} \\
\log \left(k_{\min }\right), & T>T_{\min }
\end{array} \quad\right. \text { (eq. S1) }
$$

For this study, $k_{0}$ was varied between $10^{-14}-10^{-15} \mathrm{~m}^{2}$, while $k_{\text {ductile }}$ and $k_{\min }$ were fixed at $10^{-17} \mathrm{~m}^{2}$ and $10^{-22} \mathrm{~m}^{2}$, respectively.

\section{Appendix C: Very deep intrusions}

Some simulations were performed to test the effect of intrusion emplacement depth beyond $3 \mathrm{~km}$. However, the overall thermal structure in the upper part of the system appears to be nearly identical to an analogous system with an intrusion emplaced at $3 \mathrm{~km}$ (Fig. 5g-i), with boiling above $\sim 1 \mathrm{~km}$ and isothermal upflow between 300-350 C. 